\title{
A carbon-rich region in Miller Range 091004 and implications for ureilite petrogenesis
}

James M.D. Day ${ }^{1 *}$, Christopher A. Corder ${ }^{1}$, Pierre Cartigny ${ }^{2}$, Andrew M. Steele ${ }^{3}$, Nelly Assayag $^{2}$, Douglas Rumble $\mathrm{III}^{3}$, Lawrence A. Taylor ${ }^{4}$ 
Keywords: Graphite; ureilite; MIL 091004; melt-depletion; late-stage carbon; reduction 


\section{ABSTRACT}

Ureilite meteorites are partially melted asteroidal-peridotite residues, or more rarely, cumulates that can contain greater than three weight percent carbon. Here we describe an exceptional C-rich lithology, composed of 34 modal \% large (up to $0.8 \mathrm{~mm}$ long) crystalline graphite grains, in the Antarctic ureilite meteorite Miller Range (MIL) 091004. This C-rich lithology is embedded within a silicate region composed dominantly of granular olivine with lesser quantities of low-Ca pyroxene, and minor FeNi metal, highCa pyroxene, spinel, schreibersite and troilite. Petrological evidence indicates that the graphite was added after formation of the silicate region and melt depletion. Associated with graphite is localized reduction of host olivine (Fo88-89) to nearly pure forsterite (Fo99), which is associated with FeNi metal grains containing up to 11 wt.\% Si. The main silicate region is typical of ureilite composition, with highly siderophile element (HSE) abundances $\sim 0.3 \times$ chondrite, ${ }^{187} \mathrm{Os} /{ }^{188} \mathrm{Os}$ of 0.1260 to 0.1262 and $\Delta^{17} \mathrm{O}$ of $-0.81 \pm 0.16 \%$. Mineral trace-element analyses reveal that the rare earth elements (REE) and the HSE are controlled by pyroxene and FeNi metal phases in the meteorite, respectively. Modelling of bulk-rock REE and HSE abundances indicates that the main silicate region experienced $\sim 6 \%$ silicate and $>50 \%$ sulfide melt extraction, which is at the lower end of partial melt removal estimated for ureilites. Miller Range 091004 demonstrates heterogeneous distribution of carbon at centimeter scales and a limited range in $\mathrm{Mg} /$ $(\mathrm{Mg}+\mathrm{Fe})$ compositions of silicate grain cores, despite significant quantities of carbon. These observations demonstrate that silicate rim reduction was a rapid disequilibrium process, and came after silicate and sulfide melt removal in MIL 091004. The petrography and mineral chemistry of MIL 091004 is permissive of the graphite representing late-stage $\mathrm{C}$-rich melt that pervaded silicates, or carbon that acted as a lubricant during anatexis and impact disruption in the parent body. Positive correlation of $\mathrm{Pt} / \mathrm{Os}$ ratios with olivine core compositions, but a wide range of oxygen isotope compositions, indicates that ureilites formed from a compositionally heterogeneous parent body that experienced variable sulfide and metal melt-loss that is most pronounced in relatively oxidized ureilites with $\Delta^{17} \mathrm{O}$ between -1.5 and $\sim 0 \%$. 


\section{Introduction}

Ureilite meteorites are dominantly olivine and pyroxene restites formed after early partial melting of an asteroidal parent body (e.g., Takeda, 1987; Warren \& Kalleymeyn, 1992; Scott et al., 1993; Goodrich et al., 2004). They have ancient crystallization ages placing their formation early in Solar System formation $(4.563 \mathrm{Ga}$; e.g., Torigoye-Kita et al., 1995; Budde et al., 2015). Ureilites are often considered as early-formed, asteroidal 'mantle peridotites' and are the most common partially melted achondrite group, with $>430$ recognized stones (Meteoritical Database, October 2016). What makes ureilites particularly remarkable is that elemental carbon occurs in many of these meteorites (Vdovykin, 1970; 1972; Neuvonen et al., 1972; Wlotzka, 1972; Berkley et al., 1976; 1980, Berkley \& Jones, 1982; Treiman \& Berkley, 1994; Goodrich et al., 2004). Carbon has been found interstitial to silicate minerals and can occur in high abundances within individual meteorites (average $3 \mathrm{wt} \%$ ), existing mainly as graphite, but also as amorphous carbon, organic carbon, carbides, cohenite, diamond and lonsdaleite (Berkley et al., 1976; Berkley \& Jones, 1982; Treiman \& Berkley, 1994; Mittlefehldt et al., 1998; Karczemska et al., 2009).

The origin of carbon in ureilites remains an unresolved issue. Early work established the existence of reduced rims of silicate minerals juxtaposed next to intergranular graphite, demonstrating core-rim disequilibrium and suggesting late-addition of graphite (Wlotzka, 1972), possibly through shock-induced injection (Boynton et al., 1976; Wasson et al., 1976; Tomeoka \& Takeda, 1990). The concept of secondary generation of graphite in ureilites has largely been abandoned in favour of primary origins. This change in origin can be ascribed to a lack of evidence for correlation of carbon content with degree of shock, and petrological evidence in some ureilites indicating that graphite may be primary (Berkley et al., 1980; Goodrich \& Berkley, 1986).

As well as containing carbon, ureilites exhibit several distinctive and correlated geochemical features. The first is a trend of FeO-variation in olivine core compositions $($ molar $[\mathrm{Mg} /(\mathrm{Mg}+\mathrm{Fe}) \times 100]$ of olivine from Fo74 to Fo97), suggesting variable redox 
during ureilite petrogenesis. The olivine core compositions are also associated with estimated temperatures of equilibration from low-Ca pyroxene compositions $\left(r^{2}=0.8\right.$; Singletary \& Grove, 2003; Warren, 2012). Second is the observation of significant $\Delta^{17} \mathrm{O}$ isotopic variability (-0.2 to $-2.6 \%$ ) among ureilites, which, therefore, do not lie along a mass-dependent fractionation line (e.g., Kita et al. 2004). The variability in oxygen isotopic compositions indicates that the ureilite parent body only partially melted, if all ureilites originate from the same parent body. The variation in oxygen isotopes also implies a parent body, or bodies, with highly heterogeneous starting compositions (Figure 1). The origin of these variations has been much debated, with both 'smelting' (partial melting in the presence of a reducing agent; e.g., Berkley \& Jones, 1982; Walker \& Grove, 1993; Goodrich et al., 2007; 2013) and nebular models (e.g., Warren \& Kallemeyn, 1992; Goodrich \& Delaney, 2000; Warren \& Huber, 2006; Warren, 2012) being invoked to explain ureilite compositional variations. Overall, the consensus is that ureilites are partially-melted mantle restites of a highly heterogeneous parent body that is anomalously rich in carbon (e.g., Warren and Kallemeyn 1992; Singletary \& Grove 2003; Goodrich et al. 2004; Kita et al. 2004; Warren \& Huber 2006; Warren, 2011).

In this contribution, we describe the Antarctic meteorite, Miller Range (MIL) 091004 and show that its petrogenesis has ramifications for the formation of ureilites. We describe a feature in MIL 091004 that is, to date, unique amongst any ureilite meteorite; a graphite-rich region composed of $>30$ modal \% graphite. This feature is more extensive than carbon found previously in ureilites, with petrological evidence that the graphite was introduced after the silicates in the meteorite had experienced partial melting.

\section{Sample and analytical methods}

Antarctic meteorite find Miller Range (MIL) 091004 was originally described as a lodranite (Satterwhite \& Righter, 2012). A polished thick section (MIL 091004, 7, total surface area $\left.=1.35 \mathrm{~cm}^{2}\right)$ and a bulk-rock fragment $($ MIL 091004, 4; total sample weight $=$ $1.045 \mathrm{~g})$ of MIL 091004 were obtained from the Meteorite Working Group. Determination of petrography and mineral modes was performed using a Nikon POL 
transmitted/reflected light microscope equipped with an imaging system for scaleddigitization of whole- or individual-areas of thin-sections. Mineral modes were determined using thresholds for individual minerals, calculated according to analyzed mineral compositions and then quantitatively analyzed using Image $J$ analysis software with uncertainties of better than $\pm 5 \%$ (Day et al., 2006). To identify the nature of the carbon in MIL 091004, we used Raman spectroscopy techniques, as described in Steele et al. (2007) and in the Supplementary Materials.

Major- and minor-element mineral compositions were obtained from the polished thick section at the University of Tennessee with a Cameca SX-100 electron probe micro analyzer using identical methods to those described in Day et al. (2015). Laser ablation ICP-MS analyses of mineral phases was performed using a New Wave Research UP213 $(213 \mathrm{~nm})$ laser-ablation system coupled to a ThermoScientific iCAPq C Inductively Coupled Plasma-Mass Spectrometer at the Scripps Isotope Geochemistry Laboratory $(S I G L)$. Analyses were done using spots with a $150 \mu \mathrm{m}$ beam diameter, a laser repetition rate of $5 \mathrm{~Hz}$, and a photon fluence of $3.5 \mathrm{~J} / \mathrm{cm}^{2}$. Ablation analysis took place in a $3 \mathrm{~cm}^{3}$ ablation cell. The cell was flushed with a He-gas flow to enhance production and transport of fine aerosols, and was mixed with an Ar carrier-gas flow of $\sim 1 \mathrm{~L} / \mathrm{min}$ before reaching the torch. Each analysis consisted of $\sim 60 \mathrm{~s}$ data collection. Backgrounds on the sample gas were collected for $\sim 20 \mathrm{~s}$ followed by $\sim 40 \mathrm{~s}$ of laser ablation. Washout time between analyses was $>120$ s. Data were collected in time-resolved mode so effects of inclusions, mineral zoning and possible penetration of the laser beam to underlying phases could be evaluated. Plots of counts per second versus time were examined for each analysis, and integration intervals for the gas background and the sample analysis were selected. Standardization was performed using the NIST 610 glass, BCR-2g and BHVO-2g for lithophile trace element abundances and using iron meteorite in-house standards Filomena, Hoba and Coahuila for siderophile element abundances.

The whole-rock fragment of MIL 091004, 4 was partially disaggregated to obtain small chips that were subsequently crushed with limited force in an agate mortar and pestle to make a partially representative $(\sim 0.2-0.25 \mathrm{~g})$ whole-rock powder for each sub- 
fragment. No carbon-rich material was recognized in MIL 091004, 4 during crushing. Bulk rock major- and trace-element abundances were determined on two individually prepared MIL 091004 sample powders using pressure-assisted digestion in Teflon Parr bomb vessels at the SIGL. The powder was digested at $170^{\circ} \mathrm{C}$ in Optima grade concentrated $\mathrm{HF}(4 \mathrm{~mL})$ and $\mathrm{HNO}_{3}(1 \mathrm{~mL})$ for $>72 \mathrm{hrs}$ in a processing oven along with total analytical blanks, terrestrial basalt standards and the CV3 chondrite, Allende. Samples were sequentially dried and taken up in concentrated $\mathrm{HNO}_{3}$ to remove fluorides, followed by dilution and doping with indium to monitor instrumental drift during analysis. One sample from the exterior of the meteorite was also measured by digestion in a conventional $7 \mathrm{~mL}$ Teflon vial. Major- and trace-element abundance analyses were obtained using a ThermoScientific iCAP Qc quadropole inductively coupled plasma mass spectrometer in normal mode. Analyses were standardized versus reference material BHVO-2 (see Table S5). In addition, reference materials were analyzed as "unknowns" (BIR-1, BHVO-2, and BCR-2) to assess external reproducibility and accuracy (see also Day et al., 2015). For major- and trace-elements, reproducibility of the reference materials was generally better than $6 \%$ (RSD).

Osmium isotope and HSE abundance analyses were performed at the SIGL using established methods (Day et al., 2016a) and procedures identical to those described in Day et al. (2015). Precision for ${ }^{187} \mathrm{Os} / 188 \mathrm{Os}$, determined by repeated measurement of the UMCP Johnson-Matthey standard was better than $\pm 0.2 \%$ (2 St. Dev.; $0.11390 \pm 20 ; n=$ 5). Measured Re, Ir, Pt, Pd and Ru isotopic ratios for sample solutions were corrected for mass fractionation using the deviation of the standard average run on the day over the natural ratio for the element. External reproducibility on HSE analyses was better than $0.5 \%$ for $0.5 \mathrm{ppb}$ solutions and all reported values are blank corrected. Total analytical blanks $(n=3)$ run with samples had ${ }^{187} \mathrm{Os} /{ }^{188} \mathrm{Os}=0.401 \pm 0.010$, with quantities (in picograms) of $4.2 \pm 1.3[\mathrm{Re}], 2.8 \pm 0.3[\mathrm{Pd}], 2.0 \pm 0.9[\mathrm{Pt}], 13.3 \pm 1.3[\mathrm{Ru}], 0.3 \pm 0.2[\mathrm{Ir}]$ and $0.2 \pm 0.1$ [Os]. Blanks resulted in negligible corrections to samples $(<1 \%)$.

Oxygen isotope analysis was performed at the Institut de Physique du Globe-Paris using identical methods to those described in Day et al. (2015). Oxygen isotopic ratios 
$\left({ }^{\mathrm{X}} \mathrm{O} /{ }^{16} \mathrm{O}\right.$, where $\mathrm{X}={ }^{18} \mathrm{O}$ or $\left.{ }^{17} \mathrm{O}\right)$ are measured versus international standard, V-SMOW, and expressed in $\delta$ notation, according to the following equation: $\delta^{\mathrm{x}} \mathrm{O}=1000 \times\left(\left({ }^{\mathrm{x}} \mathrm{O} /\right.\right.$ $\left.{ }^{16} \mathrm{O}\right) /\left({ }^{\mathrm{X}} \mathrm{O} /{ }^{16} \mathrm{O}_{\text {std }}\right)-1$ ). From the delta notation values, $\Delta{ }^{17} \mathrm{O}$ (in per mil, representing deviation from the terrestrial fractionation line: $\Delta^{17} \mathrm{O}=\delta^{17} \mathrm{O}-\left(\left(\delta^{18} \mathrm{O} / 1000+1\right)^{\wedge} 0.524-\right.$ 1) $\times 1000$ ) was calculated. Measurement of the San Carlos olivine and UWG-2 garnet standard aliquots gave (in per mil) uncertainties of $\delta^{17} \mathrm{O}= \pm 0.09$, on $\delta^{18} \mathrm{O}= \pm 0.17$, and for $\Delta^{17} \mathrm{O}=-0.004 \pm 0.018(2 \sigma ; n=18)$. In-run uncertainties for individual measurements were $<0.06 \%$ for $\delta^{17} \mathrm{O}$ and $<0.03 \%$ for $\delta^{18} \mathrm{O}$. Full analytical methods and tabulated data are provided in the Supplementary Materials accompanying this article.

\section{Results}

\subsection{Miller Range 091004}

Miller Range (MIL) 091004 has previously been described as having an exterior covered in $\sim 95 \%$ black/brown fusion crust, with rusty areas, and was classified as a lodranite (Satterwhite \& Righter, 2012). The polished section that we studied contains two distinct regions visible to the naked eye. The first we term the main silicate region that makes up $90 \%$ of the polished thick-section and is predominantly composed of olivine and low-Ca pyroxene, with a granular texture similar to that described for ureilites previously (e.g., Berkley et al. 1980; Goodrich 1992; Goodrich et al. 2004). The major mineral phases present in this region are low-Ca pyroxene and olivine (90 modal \%), as well as $\mathrm{FeNi}$, troilite $(\mathrm{FeS})$, and schreibersite ( 2 modal \%), with the remainder of the region (8 modal \%) containing terrestrial alteration and fusion crust (Table S1). A few small augite grains are poikiolitically enclosed within olivine. The oxide phases are dominantly hosted within veins surrounding silicate minerals. This region also has a few sub-millimeter holes and lacks carbon or spinel.

The second region, making up $10 \%$ of the polished thick-section, has an intergranular texture of numerous lathlike carbon grains (34 modal \%) in association with olivine (64 modal \%) and minor FeNi metal ( 2 modal \%). This region is referred to as the carbon-rich region, and this same region is visible in images of thick-section MIL 
091004, 2 (Satterwhite \& Righter 2012). The contact between the two regions is well defined by the presence or absence of carbon grains (Figure 2).

For the complete area of the polished-section that we studied, olivine and low-Ca pyroxene account for 87 modal \%, FeNi, FeS, and schreibersite account for 1.9 modal \%, and lathlike carbon accounts for 3.4 modal \%. The single observed augite grain makes up a small fraction of the total area $(<0.05$ modal $\%)$. The remainder of the section $(7.4$ modal \%) is comprised of material created through terrestrial weathering (this material occurs along grain boundaries and within fractures of olivines), with crystalline, vesicular fusion crust along the edge of the polished thick-section. The mineral chemistry of the meteorite is similar to ureilites studied previously, with homogeneous pyroxene compositions in equilibrium with $\sim$ Fo89 olivine (Figure 3). Within the olivine population, there is a skewed distribution to forsteritic olivine (Fo99) equal to the highest measured in ureilites (e.g., Warren \& Rubin, 2010). These olivine grains occur in the 'carbon-rich region', described below. In the following sections we sub-divide description of the regions of the meteorite into the 'main silicate region' and the 'carbon-rich region'.

\subsection{The main silicate region}

The main silicate region consists largely of olivine (Fo88-89 cores) and low-Ca pyroxene ( $\mathrm{Fs}_{10} \mathrm{Wo}_{5}$; Table 1) grains that can be as large as $2 \times 1 \mathrm{~mm}$. A few of these larger grains display minor undulatory extinction in cross-polarized light. There is a bimodal distribution of large silicate grains $(2 \times 1 \mathrm{~mm})$ and smaller grains $(>0.1 \times 0.1$ $\mathrm{mm}$ ) that is unusual for ureilites (Figure 2). Silicate inter-granular boundaries are both curved and straight, and silicate grains of all sizes often meet in triple junctions. Small, volumetrically minor, round ( $\leq 0.2 \mathrm{~mm}$ in diameter) augite grains $\left(\mathrm{Fs}_{6} \mathrm{Wo}_{37}\right)$ are poikilitically enclosed within olivine (Figure 4), and similarly sized olivine grains (Fo88) can also be found enclosed poikilitically within low-Ca pyroxene grains ( $\left.\mathrm{Fs}_{10} \mathrm{Wo}_{5}\right)$. Fracturing is pervasive in the main silicate region, with nearly every silicate grain containing at least one cross-grain fracture. Fracturing does not appear to distort the shape of grains. The main silicate region contains $\sim 1$ modal $\%$ interstitial FeNi metal that 
contains an appreciable amount of $\mathrm{Si}(1.5$ wt. \% Si; Table S2), troilite with high $\mathrm{Cr}$ content ( $6 \mathrm{wt}$ \% $\mathrm{Cr}$ ) and schreibersite that occurs as short veins between silicate grains. Troilite and schreibersite are intergrown with the more abundant FeNi metal. This FeNi metal also exists as $\mu \mathrm{m}$-sized inclusions $(\leq 10 \mu \mathrm{m}$ in diameter) and as stringers at the boundaries and within silicate grains (Figure 4). Carbon grains, such as those described below, are not present in the main silicate region and cohenite (e.g., Goodrich \& Berkley, 1986) was not observed.

\subsection{The carbon-rich region}

The carbon-rich region $\left(8.5 \times 2 \mathrm{~mm}\right.$; total surface area of $\left.0.13 \mathrm{~cm}^{2}\right)$ lies along one corner of polished section MIL 091004, 7, and is also visible in polished-section MIL 091004, 2 (Satterwhite \& Righter 2012). This region is striking in that it contains numerous large (100 $\mu \mathrm{m}$ to $800 \mu \mathrm{m}$ on long axis, $50 \mu \mathrm{m}$ to $300 \mu \mathrm{m}$ on short axis) laths of carbon, leading us to treat it as a distinct lithology. The carbon grains are identified in reflected light by their light tan colour. The remainder of the carbon-rich region consists primarily of $100 \times 100 \mu \mathrm{m}$ to $500 \times 100 \mu \mathrm{m}$ olivine grains (Fo88-99, with most olivine core compositions giving Fo88-89) that are often "darkened" around their edges and define a granular texture at their junctions when they are not in contact with carbon. In one instance in the carbon-rich region, a small and rounded (50 $\mu \mathrm{m}$ in diameter) low-Ca pyroxene grain $\left(\mathrm{Fs}_{10} \mathrm{Wo}_{5}\right)$ occurs poikilitically enclosed within an olivine grain (Fo88) (Table 1).

Due to the size and extent of the large carbon grains in this region, they exist concomitantly with the silicate grains rather than as interstitial phases, as has often been observed in other ureilites (e.g., Treiman \& Berkeley, 1994). Close inspection of the relationships between the carbon and the silicates reveals that they did not crystallize together (Figure 5). In several cases, smaller carbon laths protrude into interstitial spaces around otherwise euhedral olivine suggesting that the carbon grains developed after the olivine grains were already in place. Similarly, the granular texture of the silicates is disrupted by the carbon grains, leading to an overall 'phaneritic' texture to the carbon- 
rich region. The boundary between the carbon-rich region and the main silicate region is well-defined by a gradational boundary of limited extent (Figure 6). Combined with the observation of carbon grains cross-cutting pre-existing silicate grains, the textural observations are consistent with the carbon-rich region forming later than the main silicate region. Preferred orientations of the carbon laths (Figure 7), as well as boundaryparallel fractures within the carbon-rich region, provide further textural evidence that this region may represent a cross-cutting feature.

With the exception of one low-Ca pyroxene poikiolitically enclosed in olivine, the carbon-rich region's silicate mineralogy lacks pyroxene. The FeNi metal exists as $\mu \mathrm{m}$ sized and sub- $\mu$ m-sized grains occurring along silicate and carbon grain boundaries, and as stringers within olivine grains. The FeNi grains within the carbon-rich region, but near the boundary between the main silicate region, have relatively high Si content; 93 wt.\% $\mathrm{Fe}, \sim 4$ wt.\% Si, 2 wt.\% Ni, and $\sim 1$ wt.\% P. Blebs of FeNi metal also occur in reduction rims surrounding forsteritic olivine (Fo99; Figure 5). A notable expression of FeNi in the carbon rich region is a single $50 \times 50 \mu \mathrm{m}$ anhedral grain with up to $11 \mathrm{wt}$.\% Si and $2 \mathrm{wt}$. $\% \mathrm{Ni}$, approaching the composition of suessite $\left(\mathrm{Fe}_{3} \mathrm{Si}\right)$ (Table S2). Overall, these observations indicate strongly localized reduction in the carbon-rich region that postdates the formation of the main silicate region.

\subsection{Identification of primary carbon grains}

Confirmation and identification of the carbon grains as graphite was carried out by confocal Raman spectroscopy. The spectrum of the analyzed grain shows distinguishing disordered $\left(\mathrm{D}, \sim 1350 \mathrm{~cm}^{-1}\right)$ and ordered $\left(\mathrm{G}, \sim 1600 \mathrm{~cm}^{-1}\right)$ Raman peaks of graphitic carbon, as well as a distinguishing second-order band (2D, $\left.\sim 2700 \mathrm{~cm}^{-1}\right)$, indicating highly crystalline graphite (Figure S1). No other carbon polymorphs or SiC were noted.

\subsection{Bulk-rock compositions and mineral trace-element compositions}


Forty-five major-, minor- and trace-elements from three separately crushed fragments of MIL 091004 are reported in Table 2. The major element composition of MIL 091004 is similar to other measured ureilites, having low $\mathrm{Ca}$ and $\mathrm{Al}$ and an $\mathrm{Mg}$ number $(\mathrm{Mg} /(\mathrm{Mg}+\mathrm{Fe})$ of $0.62 \pm 0.01$ (2 St. Dev.). Incompatible trace-elements are strongly fractionated relative to $\mathrm{CI}$ chondrite, except for $\mathrm{P}, \mathrm{Sc}, \mathrm{Ti}, \mathrm{V}, \mathrm{Cr}$ and $\mathrm{W}$ (Figure S2). The measured concentrations of most elements in the three splits are similar, although the split taken from the outside of the meteorite, near the fusion crust, has high concentrations of $\mathrm{Ba}(109 \mathrm{ppm}), \mathrm{Cs}, \mathrm{Pb}$ and $\mathrm{Sr}$, and low $\mathrm{U}$, indicating terrestrial modification for these elements. Rare earth element (REE) contents for MIL 091004 are like those reported previously for ureilites (Figure 8) and are consistent with the meteorite representing a melt-depleted residue. The REE patterns in main silicate low-Ca pyroxene are slightly elevated relative to the bulk rocks, with olivine from both the carbon-rich and main silicate being virtually devoid of the REE. Modal reconstruction of heavy REE (e.g., Em, Tm, Yb) contents using the main silicate region olivine and low-Ca pyroxene gives an olivine: low-Ca pyroxene ratio $(\sim 1: 2)$ that does not match the relative abundances of the minerals in the meteorite $(>2: 1)$. This suggests that minor and unmeasured phases such as high-Ca pyroxene (augite) may contain significant fractions of the REE in MIL 091004. LA-ICP-MS of the graphite indicates that it is pure, lacking significant trace-element concentrations (Table S3).

Two separately crushed and digested splits of MIL 091004 were measured for HSE abundances and Re-Os isotopes, giving reproducible results. Abundances of Re, Os, $\mathrm{Ir}, \mathrm{Ru}$ and $\mathrm{Pt}$ are $\sim 0.3 \times \mathrm{CI}$ chondrite, and $\mathrm{Pd}$ is $\sim 0.1 \times \mathrm{CI}$ chondrite (Table 3; Figure 9). The overall CI chondrite normalized pattern for MIL 091004 is similar to previously measured ureilites (Rankenburg et al., 2008). Metal grains were measured by LA-ICPMS in the main silicate region, the carbon-rich region and in metal straddling the boundary between the two regions. All metals have high HSE abundances ( 0.9 to $10 \times$ CI chondrite) and have patterns similar to those of the bulk rock ureilites, but with relative $\mathrm{Pd}$ depletion and more elevated concentrations. Modal calculations, using the main silicate region metal composition relative to the bulk rock HSE abundance, predicts $\sim 6$ modal\% FeNi metal. This is approximately three times higher than measured in the 
meteorite and can be explained if metal was plucked or weathered from fractures in the polished section, as suggested by partially empty fractures between silicate mineral grains (e.g., Figure 4b) and by transformation of metal to weathering products in the meteorite. The measured ${ }^{187} \mathrm{Os} / 188 \mathrm{Os}$ for MIL 091004 (0.1261 to 0.1263$)$ is similar to carbonaceous chondrites, including Allende (Figure 9). However, the high measured ${ }^{187} \mathrm{Re} / 188 \mathrm{Os}$ (0.424-0.425) leads to slightly sub-chondritic initial ${ }^{187} \mathrm{Os} / 188 \mathrm{Os}$, assuming an ancient crystallization age $>4.5 \mathrm{Ga}$, implying minor disturbance of the Re-Os isotope system, consistent with weathering of metal grains, and with previously published data for achondrites indicating mobilization of $\mathrm{Re}$ and recent modification of $\mathrm{Re} / \mathrm{Os}$ during terrestrial residence (e.g., Rankenburg et al., 2008; Hyde et al., 2014; Day et al., 2016b).

Analysis of oxygen isotopes from three non-magnetic mineral splits separated from the bulk rock of MIL 091004 gave a mean $\Delta^{17} \mathrm{O}$ value of $-0.81 \pm 0.16 \%$ o $\left(\delta^{17} \mathrm{O}=3.0\right.$ $\pm 0.5 \%$ and $\delta^{18} \mathrm{O}=7.3 \pm 0.8 \%$, with uncertainty derived from replicate measurements; Table S6). The uncertainties associated with measurement of splits of MIL 091004, compared with those for terrestrial mineral standards (San Carlos Olivine, UWG-2 garnet), implies limited O-isotope heterogeneity within MIL 091004. The ureilite group has a wide range of $\Delta^{17} \mathrm{O}$ values, along a slope of $\sim 1$, suggesting a primitive origin $(-0.23$ $\%$ to $-2.45 \%$; Clayton \& Mayeda 1996), and in an oxygen three-isotope plot, the ureilite field is roughly constrained along the carbonaceous chondrite anhydrous mineral (CCAM) line, which is defined by analysis of minerals separated from Allende CalciumAluminum-Inclusions (CAIs; Clayton et al., 1977; Clayton \& Mayeda, 1999). The Oisotope systematics of MIL 091004 are consistent with it being a ureilite, with the three splits lying along the CCAM, and making it distinct from other meteorite groups (Figure 10).

\section{Discussion}

\subsection{MIL 091004 is an ureilite, not a lodranite}

Preliminary classification of MIL 091004 identified it as a lodranite (Satterwhite \& Righter, 2012). Oxygen isotope compositions do not support this classification (Figure 
10). Instead, the texture, mineral chemistry and whole-rock geochemistry described here are consistent with MIL 091004 being a new ureilite.

\subsection{Augite in MIL 091004 and comparison with 'Hughes cluster' ureilites}

A feature of the mineralogy of MIL 091004 is the presence of small high-Ca pyroxene (augite) grains within other silicate phases (e.g., Figure 4). Augite has previously been reported in ureilites including Hughes 009, Lewis Cliff (LEW) 85440 (paired with LEW 88012, LEW 88201, LEW 88281), Allan Hills (ALH) 82106 (paired with ALH 82130 and ALH 84136), Elephant Moraine (EET) 87511 (paired with EET 87523 and EET 87717), HaH 064, Meteorite Hills (META) 78008, Yamato (Y-)74130, LEW 88774, EET 87517, EET 96293, EET 96314 and EET 96331 (Mittlefehldt et al., 1998; Goodrich et al., 2004; Downes et al., 2008). Three of these augite-bearing ureilites are pyroxenites, rather than peridotites (HaH 064, Y-74130, Hughes 009), and these and some non-augite bearing ureilites with poikilitic or bi-modal textures, have been interpreted to result from crystal accumulation, or melt impregnation (Downes et al., 2008). This so-called 'Hughes cluster' of ureilites is considered to have formed by meltrelated processes, rather than by formation as depleted restites.

Augite grains in the main silicate region of MIL 901004 are volumetrically minor and occur as rounded 'inclusions' within olivine grains (Figure 4), contrasting strongly with augite grains that are found along grain boundaries, or as discrete veins within some ureilites (see discussion in Downes et al., 2008). Our observations show that a crystal accumulation or impregnation origin for these augites is not possible. The augite grains are typically small ( $<200 \mu \mathrm{m}$ diameter) and always occur enclosed within, and are in $\mathrm{Mg}$ / $(\mathrm{Mg}+\mathrm{Fe})$ equilibrium with, olivine and orthopyroxene. These relationships imply that the augite is a residual phase, preserved from complete exhaustion during partial melting through armouring by other silicate phases. Armouring of the augite likely occurred during thermal annealing, leading to the formation of larger grains at the expense of small grains. This explanation also matches the unusual bi-modal distribution of silicate grains 
that characterizes the main silicate region, implying lack of complete textural equilibration. Our interpretation of the augite grains supports a depleted partial melt residue origin for MIL 091004, and also indicates lower degrees of silicate partial melting and melt extraction than typically experienced by some granular ureilites that lack highCa pyroxene.

\subsection{Petrogenesis of MIL 091004}

To examine the petrogenesis of MIL 091004, we employed a similar rare earth element (REE) modeling approach to that used in previous studies (Spitz \& Boynton, 1991; Warren \& Kallemeyn, 1992; Goodrich et al., 2007). These studies used broadly similar REE partition coefficients (Table S7) and a CI-chondrite starting composition similar to those applied here, but initial modal abundance of major silicate phases (e.g., olivine, low-Ca pyroxene, high-Ca pyroxene, Al-rich phases) and the style of melting (cf., batch melting, instantaneous non-model fractional melting; see Warren \& Kalleymeyn, 1992) have varied in models. We applied a non-modal fractional melting model, due to the evidence for nearly-complete exhaustion of high-Ca pyroxene (augite; see section 4.2). Prior studies have used elevated proportions of Al-rich phases (e.g., Spitz \& Boynton, 1991; Warren \& Kalleymeyn, 1992), leading to different mineral exhaustion trends, predicting loss of Al-rich phases at between $\sim 4 \%$ and $\sim 16 \%$ melting. However, the effect of Al-rich phases is limited on REE partitioning compared with highCa pyroxene. Our model suggests that the degree of melt-loss from ureilites ranges between 4 to 15\%, with MIL 091004 experiencing approximately $6 \%$ silicate melt depletion, based on whole-rock HREE concentrations (Figure 8).

The HSE can become strongly chalcophile (e.g., Day et al., 2016b), and are sensitive tracers of the earliest stages of partial melting in chondrites, when the first melts to be generated are Fe-Ni-S-rich (e.g., Mittlefehldt et al., 1996). The distribution of HSE between a liquid-metal phase and solid-metal restite during partial melting in the Fe-Ni-S system is dependent on the $\mathrm{S}$ content of extracted melts, and on $\mathrm{C}$ and $\mathrm{P}$ that enter the 
metallic phase (Chabot \& Jones, 2003). Fractionation of the HSE in ureilites probably reflects partial extraction of metal liquids of variable $\mathrm{S}$ content from a chondritic starting composition. To explore this possibility, we modelled batch-melting of metal with FeS removal and resultant residues using solid metal-liquid metal D-values from the parameterization of Chabot \& Jones (2003). The approach is similar to a previous study that modelled variable S contents during metal melt removal in ureilites (Rankenburg et al., 2008).

For the starting composition, we use CI chondrite, Orgueil, due to its relatively elevated $\mathrm{Pd} / \mathrm{Os}(\sim 1.3)$ implying a primitive composition, and assumed that all HSE were initially sited in metal. In reality, CI chondrite is an impossible starting composition for ureilites, given their distinct $\mathrm{Cr}, \mathrm{O}$ and $\mathrm{Ti}$ isotope signatures (Warren et al., 2011). Nonetheless, the absolute HSE abundances of chondrite meteorite groups are limited ( 30-40\%; Day et al., 2016b) and, since the ureilite precursor compositions has not been identified, suggests that HSE abundances in CI chondrite are an approximation of ureilite starting compositions. We used HSE partitioning between solid metal and liquid metal, consistent with high D-values for the HSE $\left(>10^{4}\right)$ for metal-silicate at the low pressures of asteroidal interiors (e.g., Righter, 2003).

The HSE preferentially partition into metal with the HSE concentration present in the metal dependent on the percentage of metal in the parent body, as a function of oxidation state. To estimate initial metal abundance, we used the approach of Rankenburg et al. (2008), comparing total $\mathrm{Fe}$ and olivine composition in ureilites with the total $\mathrm{Fe}$ content of carbonaceous chondrites (e.g., Orgueil), which have relatively constant total Fe of $\sim 24.5 \pm 1.5$ wt.\% (Jarosewich, 1990). The results are consistent with S-rich melt removal from ureilites, with MIL 091004 having one of the lowest levels of melt depletion (Figure 11). 
Comparison of estimates of silicate and Fe-Ni-S melting for ureilites indicates those with the lowest silicate melt loss have the highest Pt/Os (Figure S3), suggesting limited sulfide ( \pm metal) removal. These relationships are consistent with limited silicate (4-15\%), and limited to extensive sulfide ( \pm metal) $(>50 \%)$ partial melt removal in ureilites. We also find that ureilites that experienced the highest levels of melt depletion are those with the lowest $\mathrm{Mg} /(\mathrm{Fe}+\mathrm{Mg})$ olivine core compositions and highest $\Delta^{17} \mathrm{O}$ (Figure 12). MIL 091004 falls in the range of the least melt-depleted ureilites in Figure 12. It has both geochemical and petrological evidence (presence of included augite, bimodal silicate grain sizes) for limited silicate melt loss. Comparisons of melt depletion with olivine core composition therefore suggest a potential issue in the interpretation of ureilite equilibration temperatures. Previously, Singletary \& Grove (2003) experimentally calibrated equilibration temperatures in ureilites using a low-Ca pyroxene thermometer. This thermometer indicates highest temperatures of equilibration in ureilites with high $\mathrm{Mg} /(\mathrm{Mg}+\mathrm{Fe})$ olivine core compositions and the most negative $\Delta^{18} \mathrm{O}$ (Figure 1). This trend is opposite to that of modelled melt depletion. These results suggest that the low-Ca pyroxene thermometer is incorrect for MIL 091004 because ureilite olivine core compositions do not simply reflect the temperatures of equilibration assumed in partial melting/smelting models (cf., Singletary \& Grove, 2003; Goodrich et al., 2013).

\subsection{Evidence for a late-stage origin for carbon grains in MIL 091004}

There are three main lines of evidence for the late-stage addition of carbon to MIL 091004. First, the carbon is concentrated in a single location within the polished section that we examined, as well as in MIL 091004, 2 (Satterwhite \& Righter, 2012), with carbon grains showing broad parallelism with the boundaries of the main silicate region and the carbon-rich region (e.g., Figure 1). This parallelism would appear to reflect an active process (e.g., Lindgren \& Parnell, 2006). This could either suggest pressure gradients induced from injection, or shear stresses from imbrication of the graphite during 'hot jumbling' and disruption of the ureilite parent body. Second, the graphite appears to have been injected (Figure 6), or smeared (Figure 5) into the main silicate 
region. The continuity of the bimodal granular texture and mineral compositions for olivine and low-Ca pyroxene in the carbon-rich region, compared with the main silicate region, indicates that the carbon was introduced into the silicates within the carbon-rich region after they had attained their $\mathrm{Mg} /(\mathrm{Mg}+\mathrm{Fe}$ ) character (olivine core compositions = Fo88-89 and low-Ca pyroxene of $\mathrm{En}_{85} \mathrm{Wo}_{5}$ ).

Third, and perhaps chiefly, there is not a diffuse reduction gradient from the carbon-rich region into the main silicate region. Such a gradient, or complete equilibration, would be anticipated if carbon was a primary feature of the sample, given the melt depletion experienced by the sample, consistent with temperatures of $>1000^{\circ} \mathrm{C}$. The reduction gradients for the silicates are relatively sharp. For example, olivine core compositions within the carbon-rich region are Fo88-89 near (10-100's $\mu \mathrm{m})$ to graphite grains. These observations demonstrate that rim-reduction of silicate phases in the carbon-rich region occurred after the emplacement of graphite, with rim reduction observed only in the final few $\mu \mathrm{m}$ of olivine next to FeNi metal in the main silicate region. Injection or addition of the graphite must therefore have been extremely rapid. Similarly, cooling after addition of the graphite must also have been rapid. For example, in the carbon-rich region, a significant proportion of graphite was available, yet only around one-third of the olivine was reduced based on modal analysis (Table S1) whereas, in the main silicate region, extremely limited rim reduction occurred (e.g., Figure 4). These observations suggest that the inferred equilibration pressure of 55 to 60 bar for MIL 091004 is likely to be incorrect (Figure S4), as the barometer was calibrated assuming reduction of olivine core compositions in response to smelting (Walker \& Grove, 1993). Given the late-stage origin of carbon in MIL 091004, we compare our observations with carbon occurrences in ureilites and terrestrial samples to examine latestage origins for carbon.

\subsection{Implications for carbon in ureilites}

Many ureilites contain significant quantities of carbon, averaging 3 wt.\%, (Vdovykin, 1970; 1972; Neuvonen et al., 1972; Wlotzka, 1972; Berkley et al., 1976; 
1980, Berkley \& Jones, 1982; Treiman \& Berkley, 1994; Mittlefehldt et al., 1998; Goodrich et al., 2004; Karczemska et al., 2009). In most cases, carbon grains are distributed around reduced silicate phases, or occur in distinct clusters of limited size, rather than as concentrated masses, as is the case for MIL 091004. An unusual carbonaceous vein (0.2-0.4 $\mathrm{mm}$ wide and $4.6 \mathrm{~mm}$ in length) was reported in augitebearing ureilite Y-74130, by Tomeoka \& Takeda (1990). These authors reported that the vein intruded low-Ca pyroxene in which reduction had generated enstatite and 'Fe-rich beads'. The vein described in Y-74130 is clearly distinct from the carbon-rich region in MIL 091004, as it had S-, Fe-S-, and Al-rich veins within it. This vein has a late-stage origin associated with impact injection (Tomeoka \& Takeda, 1990).

There is also evidence for late-stage addition of carbon in terrestrial mantle rocks. Since terrestrial igneous rocks typically form at relatively high oxygen fugacities (>FMQ), most terrestrial igneous graphite occurs in rocks that formed at relatively high pressures and/or low $\mathrm{fO}_{2}$. Graphite, diamond and $\mathrm{SiC}$ are, therefore, rare constituents of terrestrial igneous rocks, primarily occurring as metasomatic minerals in mafic and ultramafic xenoliths in kimberlites and alkali basalts (e.g., Hatton \& Gurney, 1979; Robinson, 1979; Kornprobst et al., 1987; Pearson et al., 1990; Field \& Haggerty, 1990; Shirey et al., 2013; Cartigny et al., 2014; Shiryaev \& Gaillard, 2014), rarely, as intercumulus regions of layered intrusions (e.g., Hollister, 1980; Balhaus \& Stumpfl, 1985), or as a consequence of igneous melt-carbonaceous sediment interactions (e.g., Bird et al., 1981). Field \& Haggerty (1990) described a graphite-free mantle peridotite cut by a graphite-bearing eclogite vein. Graphite euhedra spanning grain-boundaries in the veinlet were interpreted to have crystallized from the basaltic magma that formed the eclogite.

Our observations indicate that the carbon-rich region in MIL 091004 was introduced into the main silicate region after silicate and Fe-Ni-S melt depletion. There are several potential mechanisms by which carbon could be added to partially melted ureilites. In all instances, carbon retention against oxidation presumably required attainment of relatively high pressures in advance of high internal temperatures in 
ureilites, suggesting a relatively large parent body (Warren, 2011). The most likely scenario would be from localized oxidation/reduction reactions involving the C-CO-CO 2 system $\left(\mathrm{CO}_{2}=\mathrm{C}+\mathrm{O}_{2}\right.$; e.g., Mittlefehldt, 1986), although methane reduction is also possible $\left(\mathrm{CH}_{4}+\mathrm{O}_{2}=\mathrm{C}+\mathrm{H}_{2} \mathrm{O}\right)$. Reactions might also include reactions of $\mathrm{SiC}$ such that: $6 \mathrm{C}+4 \mathrm{MgSiO}_{3}=2 \mathrm{SiC}+6 \mathrm{CO}+2 \mathrm{Mg}_{2} \mathrm{SiO}_{4}($ Shiryaev \& Gaillard, 2014)

Tomeoka and Takeda (1990) proposed that the vein in Y-74130 may have acted as a conduit or 'drainage channel' where $\mathrm{C}$ would remain in the system as non-volatile graphite. They further suggested that, since $\mathrm{C}$-veins are more compressible than silicates, they were preferentially deformed and cracked. Melt migration is predicted even in small asteroidal bodies, as the low velocity of melt migration is counteracted by the short distance over which the melt must travel (e.g., Moskovitz \& Gaidos, 2011). Indeed, Wilson et al. (2008) have argued for efficient melt networks to form on the ureilite parent body, including veins and dikes. Introduction of $\mathrm{C}$ after the main phase(s) of partial melting on the ureilite parent body would explain the poor correlation with $\mathrm{C}$ content and olivine core compositions in ureilites (e.g., Warren \& Huber, 2006), as no correlation would be anticipated from heterogeneous late-stage addition of carbon.

Infiltration of a C-rich material sometime after initial melt depletion, either from C-rich fluids, from injection events during impact (e.g., Boynton et al., 1976; Wasson et al., 1976; Tomeoka \& Takeda, 1990), or from impact disruption and jumbling are all possible explanations for the carbon-rich region in MIL 091004. All would presumably lead to layer parallelism of graphite grains. All would have been rapid events leading to great variation in carbon abundance over short distances but limited silicate $\mathrm{Mg} /(\mathrm{Mg}+\mathrm{Fe})$ diversity. Distinguishing between these different possibilities is currently difficult (e.g., Lindgren \& Parnell, 2006). Perhaps one potential argument against an interior melt origin for the graphite is that the source of the carbon must have had a high carbon content to dilute the $\mathrm{C}$ component down to the final ureilite range of $\sim 3 \mathrm{wt} \%$ (6 vol.\%). Conversely, carbon-rich metasomatism, including graphite and diamond precipitation, has been observed in terrestrial mantle rocks, such as peridotites, without the requirement for an extremely C-rich reservoir. Instead, low degree partial melts or C-rich fluid with 
high fluid/rock ratios can precipitate graphite, accounting for the high final abundance of carbon.

The evidence for late-stage addition of C to MIL 091004 indicates that ureilites may be a useful analogue with carbon occurrences in the terrestrial mantle, or vice-aversa. Models of carbon or $\mathrm{SiC}$ addition in terrestrial peridotites do not require high pressures, but reducing conditions (IW-6; e.g., Shiryaev \& Gaillard, 2014), often in the presence of C-O-H-N-S rich fluids (e.g., Cartigny et al., 2014). In detail, such occurrences are distinct from MIL 091004, forming from carbon-rich melt-infiltration in a terrestrial plate-tectonic setting. The evidence for a late-stage origin for the graphite in MIL 091004 and evidence for similar processes acting on other ureilites and in previously melt-depleted terrestrial mantle rocks, offers the possibility that $\mathrm{C}$ in some ureilites may have been introduced after the anatexis and partial melting of the silicate mineral phases.

\section{Conclusions}

Miller Range 091004 is a ureilite that contains an exceptional lithology with 34 modal $\%$ graphite. The graphite is a late-stage addition, after approximately $6 \%$ silicate and $>50 \%$ sulfide partial melt-loss had occurred. Evidence for late addition of the graphite includes strongly localized reduction, with olivine core compositions of Fo88-89 and reduced regions up to Fog9 and associated FeNi grains with up to 11 wt.\% Si in the carbon-rich region. The olivine core compositions of the carbon-rich region are identical to the carbon-free main silicate region, as are the low-Ca pyroxene compositions in the two regions (En85 Wo5). This suggests that MIL 091004 (and other ureilites) olivine core compositions were not reduced. Miller Range 091004 demonstrates that significant variation in carbon abundance existed over short distances within the ureilite parent body and that this diversity is accompanied by minor silicate $\mathrm{Mg} /(\mathrm{Fe}+\mathrm{Mg})$ diversity. Experimentally determined olivine-carbon reduction barometry does not apply to MIL 091004. We also find a positive relationship with $\mathrm{Pt} / \mathrm{Os}$ and olivine core compositions, implying that melt-loss is inversely related to $\Delta^{17} \mathrm{O}$ in ureilites. The ureilites with the lowest $\Delta{ }^{17} \mathrm{O}$ values and highest olivine core compositions $(\mathrm{Fo}>85)$ are some of the least 
melt-depleted. We interpret the petrogenesis of MIL 091004 to reflect: (1) highly heterogeneous (reduced and oxidized materials) accretion of the ureilite parent body; (2) variable and limited partial melting and melt-depletion to form the majority $(>70 \%)$ of ureilites under relatively more oxidized conditions; (3) late-stage C-rich fluid/melt infiltration or physical mixing and limited silicate reduction to form the carbon-rich region and localized reduction of silicates and metals; (4) impact-removal from the parent body, space transit, and fall and recovery on the Antarctic Ice. The evidence for late-stage addition of carbon to MIL 091004 indicates that ureilites may be a possibly useful analogue for understanding the role of carbon metasomatism in the terrestrial mantle, as well as for other planetary bodies.

\section{Acknowledgements}

We thank the Meteorite Working Group for provision of MIL 091004. US Antarctic meteorite samples are recovered by the Antarctic Search for Meteorites (ANSMET) program which has been funded by NSF and NASA, and characterized and curated by the Department of Mineral Sciences of the Smithsonian Institution and Astromaterials Curation Office at NASA Johnson Space Center. Comments made on versions of this manuscript by J.-A. Barrat, H. Downes, C. Goodrich, D. Mittlefehldt, P. Warren and an anonymous reviewer are gratefully acknowledged. We are especially grateful to P. Warren for highly constructive suggestions and suggesting 'hot jumbling'. Support for this work came from NASA Cosmochemistry and Emerging Worlds (NNX12AH75G \& NNX15AL74G to JMDD and NNX11AG586 to LAT). Day and Rumble both thank the IPGP/Universite Paris Diderot for support as Visiting Professors.

\section{REFERENCES}

Balhaus, C., Stumpfl, E.F., 1985. Occurrence and petrological significance of graphite in the Upper Critical Zone, Western Bushveld Complex, South Africa. Earth and Planetary Science Letters, 74, 58-68.

Benedix, G.K., McCoy, T.J., Keil, K., Bogard, D.D., Garrison, D.H., 1998. A petrologic and isotopic study of winonaites: evidence for early partial melting, brecciation, and metamorphism. Geochimica et Cosmochimica Acta, 62, 2535-2553. 
Berkley, J.L., Jones, J.H. 1982. Primary igneous carbon in ureilites: Petrological implications. Journal of Geophysical research 87, A353-A364.

Berkley, J.L., Taylor, G.J., Keil, K., 1980. The nature and origin of ureilites. Geochimica et Cosmochimica Acta 44, 1579-1597.

Berkley, J.L., Brown, H.G., Keil, K., Carter, N.L., Mercier, J-C.C. 1976. The Kenna ureilite: an ultramafic rock with evidence for igneous, metamorphic, and shock origin. Geochimica et Cosmochimica Acta, 40, 1429-1437.

Bird, J.M., Goodrich, C.A., Weathers, M.S., 1981. Petrogenesis of Uivfaq iron, Disko Island, Greenland. Journal of Geophysical Research: Solid Earth, 86, 11787-11805.

Boynton, W.V., Starzyk, P.M., Schmidt, R.A., 1976. Chemical evidence for the genesis of the ureilites, the achondrite Chassigny and the nakhlites. Geochimica et Cosmochimica Acta, 40, 1439-1447.

Cartigny, P., Palot, M., Thomassot, E., Harris, J.W., 2014. Diamond Formation: a stable isotope perspective. Annual Reviews in Earth and Planetary Sciences, 42, 699-732.

Chabot, N.L., Jones, J.H., 2003. The parameterization of solid metal-liquid metal partitioning of siderophile elements. Meteoritics and Planetary Science, 38, 14251436.

Clayton, R.N., 2003. Oxygen isotopes in meteorites. In Treatise on Geochemistry, vol. 1 (ed. A. W. Davis). Oxford University Press, Oxford, pp. 129-142.

Clayton, R.N., Mayeda, T.K., 1996. Oxygen isotope studies of achondrites. Geochimica et Cosmochimica Acta 60, 1999-2017.

Clayton, R.N., Mayeda, T.K., 1999. Oxygen isotope studies of carbonaceous chondrites. Geochimica et Cosmochimica Acta 63, 2089-2104.

Clayton, R.N., Onuma, N., Grossman, L., Mayeda, T.K., 1977. Distribution of the presolar component in Allende and other carbonaceous chondrites. Earth and Planetary Science Letters 34, 209-224.

Day, J.M.D., Floss, C., Taylor, L.A., Anand, M., Patchen, A.D., 2006. Evolved mare basalt magmatism, high $\mathrm{Mg} / \mathrm{Fe}$ feldspathic crust, chondritic impactors, and the petrogenesis of Antarctic lunar breccia meteorites Meteorite Hills 01210 and Pecora Escarpment 02007. Geochimica et Cosmochimica Acta, 70, 5957-5989.

Day, J.M.D., Ash, R.D., Liu, Y., Bellucci, J.J., Rumble, D. III., McDonough, W.F., Walker, R.J., Taylor, L.A., 2009. Early formation of evolved asteroidal crust. Nature, 457, 179-182.

Day, J.M.D., Walker, R.J., Ash, R.D., Liu, Y., Rumble, D., Irving, A.J., Goodrich, C.A., Tait, K., McDonough, W.F., Taylor, L.A., 2012. Origin of felsic achondrites Graves Nunataks 06128 and 06129 and ultramafic brachinites and brachinite-like achondrites by partial melting of volatile-rich primitive parent bodies. Geochimica et Cosmochimica Acta, 81, 94-128.

Day, J.M.D., Corder, C.A., Rumble, D., Assayag, N., Cartigny, P., Taylor, L.A., 2015. Differentiation processes in FeO-rich asteroids revealed by the achondrite Lewis Cliff 88763. Meteoritics and Planetary Science, 50, 1750-1766.

Day J.M.D., Waters C. L., Schaefer B. F., Walker R. J., Turner, S., 2016a. Use of Hydrofluoric acid desilicification in the determination of highly siderophile element 
abundances and Re-Pt-Os isotope systematics in mafic-ultramafic Rocks. Geostandards and Geoanalytical Research, 40, 49-65.

Day J.M.D., Brandon A.D., Walker R.J., 2016b. Highly Siderophile Elements in Earth, Mars, the Moon, and Asteroids. Reviews in Mineralogy and Geochemistry 81, 161-238.

Downes, H., Mittlefehldt, D.W., Kita, N.T., Valley, J.W., 2008. Evidence from polymict ureilite meteorites for a disrupted and re-accreted single ureilite parent asteroid gardened by several distinct impactors. Geochimica et Cosmochimica Acta, 72, 4825-4844.

Field, S.W., Haggerty, S.E., 1990. Graphitic xenoliths from the Jagersfontein kimberlite, South Africa: Evidence for dominantly anhydrous melting and carbon deposition (abstract). EOS, 71, 658.

Fischer-Gödde, M., Becker, H., Wombacher, F., 2010. Rhodium, gold and other highly siderophile element abundances in chondritic meteorites. Geochimica et Cosmochimica Acta, 74, 356-379.

Floss, C., Taylor, L.A., Promprated, P., Rumble, D., 2005. Northwest Africa 011: A "eucritic" basalt from a non-eucrite parent body. Meteoritics and Planetary Science, 40, 343-360.

Gardner-Vandy, K.G., Lauretta, D.S., Greenwood, R.C., McCoy, T.J., Killgore, M., Franchi, I.A., 2012. The Tafassasset primitive achondrite: Insights into initial stages of planetary differentiation. Geochimica et Cosmochimica Acta, 2012, 142-159.

Goodrich, C.A., 1992. Ureilites: A critical review. Meteoritics 27, 327-352.

Goodrich, C.A., Berkley, J.L., 1986. Primary magmatic carbon in ureilites: evidence from cohenite-bearing metallic spherules. Geochimica et Cosmochimica Acta, 50, 681-691.

Goodrich, C.A., Delaney, J.S., 2000. Fe/Mg-Fe/Mn relations of meteorites and primary heterogeneity of primitive achondrite parent bodies. Geochimica et Cosmochimica Acta, 64, 2255-2273.

Goodrich, C.A., Jones, J.H., Berkley, J.L., 1987. Origin and evolution of the ureilite parent magmas: multi-stage igneous activity on a large parent body. Geochimica et Cosmochimica Acta, 51, 2255-2273.

Goodrich, C.A., Scott, E.R.D., Fioretti, A.M., 2004. Ureilitic breccias: clues to the petrologic structure and impact disruption of the ureilite parent asteroid. Chemie der Erde 64, 283-327.

Goodrich, C.A., Van Orman, J.A., Wilson, L., 2007. Fractional melting and smelting on the ureilite parent body. Geochimica et Cosmochimica Acta, 71, 2876-2895.

Goodrich, C.A., Hutcheon, I.D., Kita, N.T., Huss, G.R., Cohen, B.A., Keil, K., 2010. ${ }^{53} \mathrm{Mn}-{ }^{53} \mathrm{Cr}$ and ${ }^{26} \mathrm{Al}-{ }^{26} \mathrm{Mg}$ ages of a feldspathic lithology in polymict ureilites. Earth and Planetary Science Letters, 295, 531-540.

Goodrich, C.A., Wilson, L., Van Orman, J.A., Michel, P., 2013. Comment on "Parent body depth-pressure-temperature relationships and the style of ureilite anatexis" by P.H. Warren (MAPS 47:209-227). Meteoritics \& Planetary Science, 47, 1-11.

Goodrich, C.A., Hartmann, W.K., O’Brien, D.P., Weidenschilling, S.J., Wilson, L., Michel, P., Jutzi, M., 2015. Origin and history of ureilitic material in the solar system: 
the view from asteroid $2008 \mathrm{TC}_{3}$ and the Almahata Sitta meteorite. Meteoritics and Planetary Science, 50, 782-809.

Greenwood, R.C., Franchi, I.A., Gibson, J.M., Benedix, G.K., 2012. Oxygen isotope variation in primitive achondrites: The influence of primordial, asteroidal and terrestrial processes. Geochimica et Cosmochimica Acta 94, 146-163.

Hatton, C.J., Gurney, J.J., 1979. A diamond-graphite eclogite from the Roberts Victor Mine. In The Mantle Sample: Inclusions from Kimberlites and Other Volcanics (F.R. Boyd \& H.O.A. Meyer, eds.), pp. 29-36. American Geophysical Union.

Hollister, V.F., 1980. Origin of graphite in the Duluth Complex. Economic Geology, 75, 764-6.

Horan, M.F., Walker, R.J., Morgan, J.W., Grossman, J.N., Rubin, A.E., 2003. Highly siderophile elements in chondrites. Chemical Geology, 196, 5-20.

Hyde B.C., Day J.M.D., Tait K.T., Ash R.D., Holdsworth D.W., Moser D.E., 2014. A study of weathering and heterogeneous mineral phase distribution in brachinite Northwest Africa 4872. Meteoritics and Planetary Science, 49, 1141-1156.

Jones, J.H., 1995. Experimental trace element partitioning. In: Rock physics and phase relations. A handbook of physical constraints. American Geophysical Union, Washington DC, pp. 73-104.

Karczemska, A., Jakubowski, T., Vergas, F., 2009. Different diamonds in meteorites DaG 868 and NWA 3140 ureilites. Journal of Achievements in Materials and Manufacturing Engineering, 37, 292-297.

Kita, N.T., Ikeda, Y., Togashi, S., Liu, Y., Morishita, Y, Weisberg, M.K., 2004. Origin of ureilites inferred from a SIMS oxygen isotopic and trace element study of clasts in Dar al Gani 319 polymict ureilite. Geochimica et Cosmochimica Acta, 68, 4213-4235.

Kornprobst, J., Pineau, F., Degiovanni, R. and Dautria, J.M., 1987. Primary igneous graphite in ultramafic xenoliths: I. Petrology of the cumulate suite in alkali basalt near Tissemt (Eggere, Algerian Sahara). Journal of Petrology, 28, 293-311.

Lindgren, P., Parnell, J., 2006. Petrographic criteria for fluid mobility of graphitic carbon in terrestrial and extraterrestrial samples. Journal of Geochemical Exploration, 89, 235-238.

McDonough, W.F., Sun, S.-S., 1995. The composition of the Earth. Chemical Geology, 120, 223-254.

McSween, H.Y., Labotka, T.C., 1993. Oxidation during metamorphism of the ordinary chondrites. Geochimica et Cosmochimica Acta, 57, 1105-1114.

Mittlefehldt, D.W., 1986. Fe-Mg-Mn relations of ureilite olivines and pyroxenes and the genesis of ureilites. Geochimica et Cosmochimica Acta, 50, 107-110.

Mittlefehldt, D.W., Lindstrom, M.M., Bogard, D.D., Garrison, D.H., Field, S.W., 1996. Acapulco- and Lodran-like achondrites: petrology, geochemistry, chronology and origin. Geochimica et Cosmochimica Acta, 60, 867-882.

Mittlefehldt, D.W., McCoy, T.J., Goodrich, C.A., Kracher, A., 1998. Non-chondritic meteorites from asteroidal bodies. In: Planetary Materials (Ed. Papike, J.J.). Reviews in Mineralogy, 36. pp. 1-495. 
Moskovitz, N., Gaidos, E., 2011. Differentiation of planetesimals and the thermal consequences of melt migration. Meteoritics and Planetary Science, 46, 903-918.

Neuvonen, K.J., Ohlson B., Papunen, H., Kakli, T.A., Ramdohr, P., 1972. The Havero ureilite. Meteoritics, 7, 515-531.

Pearson, D.G., Boyd, F.R., Nixon, P.H., 1990. Graphite-bearing mantle xenoliths from the Kaapvaal Craton: Implications for graphite and diamond genesis. Annual Report of the Geophysical Laboratory, Carnegie Institution of Washington 1989-1990, 11-19.

Pearson, V.K., Sephton, M.A., Franchi, I.A., Gibson, J.M., Gilmour, I., 2006. Carbon and nitrogen in carbonaceous chondrites: elemental abundances and stable isotopic compositions. Meteoritics and Planetary Science, 41, 1899-1918.

Rankenburg, K., Brandon, A.D., Humayun, M., 2007. Osmium isotope systematics of ureilites. Geochimica et Cosmochimica Acta, 71, 2402-2413.

Rankenburg, K., Humayun, M., Brandon, A.D., Herrin, J.S., 2008. Highly siderophile elements in ureilites. Geochimica et Cosmochimica Acta, 72, 4642-4659.

Righter, K. 2003. Metal-Silicate Partitioning of Siderophile Elements and Core Formation in the Early Earth. Annual Review of Earth and Planetary Sciences, 31(1), 135-174.

Robinson, D.N., 1979. Diamond and graphite in eclogite xenoliths from kimberlite. In The Mantle Sample: Inclusions in Kimberlites and Other Volcanics (F.R. Boyd \& H.O.A. Meyer, eds.), pp. 50-8. American Geophysical Union.

Rumble, D., Farquhar, J., Young, E.D., Christensen, C.P., 1997. In situ oxygen isotope analysis with an excimer laser using $\mathrm{F}_{2}$ and $\mathrm{BrF}_{5}$ reagents and $\mathrm{O} 2$ gas as analyte. Geochimica et Cosmochimica Acta, 61, 4229-4234.

Satterwhite, C.E., Righter, K., 2012. Antarctic Meteorite Newsletter 35(2), 1-25.

Scott, E.R.D., Taylor, G.J., Keil, K., 1993. Origin of ureilite meteorites and implications for planetary accretion. Geophysical Research Letters 20, 415-418.

Shirey, S.B., Cartigny, P., Frost, D.J., Keshav, S., Nestola, F., Nimis, P., Pearson, D.G., Sobolev, N.V., Walker, M.J., 2013. Diamonds and the geology of mantle carbon. Reviews in Mineralogy and Geochemistry, 75, 355-421.

Shiryaev, A.A., Gaillard, F., 2014. Local redox buffering by carbon at low pressures and the formation of moissanite - natural SiC. European Journal of Mineralogy, 26, 53-59.

Singletary, S.J., Grove, T.L., 2003. Early petrologic processes on the ureilite parent body. Meteoritics and Planetary Science 38, 95-108.

Smoliar, M.I., Walker, R.J., Morgan, J.W., 1996. Re-Os ages of group IIA, IIIA, IVA and IVB iron meteorites. Science 271, 1099-1102.

Spitz, A.H., Boynton, W.V., 1991. Trace element analysis of ureilites: New constraints on their petrogenesis. Geochimica et Cosmochimica Acta 55, 3417-3430.

Steele, A., Fries, M.D., Amundsen, H.E.F., Mysen, B.O., Fogel, M.L., Schweizer, M., Boctor, N.Z., 2007. Comprehensive imaging and Raman spectroscopy of carbonate globules from Martian meteorite ALH 84001 and a terrestrial analogue from Svalbard. Meteoritics and Planetary Science, 42,1549-1566.

Takeda, J., 1987. Mineralogy of Antarctic ureilites and a working hypothesis for their origin and evolution. Earth and Planetary Science Letters, 81, 358-370. 
Tomeoka, K., Takeda, H., 1990. Fe-S-Ca-Al-bearing carbonaceous vein in the Yamato-74130 ureilite: Evidence for a genetic link to carbonaceous chondrites. Geochimica et Cosmochimica Acta, 54, 1475-1481.

Torigoye-Kita, M., Tatsumoto, M., Meeker, G.P., Yanai, K., 1995. The $4.56 \mathrm{Ga}$ U-Pb age of the MET 78008 ureilite. Geochimica et Cosmochimica Acta, 59, 2319-2329.

Treiman, A.H., Berkley, J.L., 1994. Igneous petrology of the new ureilites Nova 001 and Nullarbor 010. Meteoritics, 29, 848-848.

Vdovykin, G.P., 1970. Ureilites. Space Science Reviews, 10, 483-510.

Vdovykin, G.P., 1972. Forms of carbon in the new Havero ureilite in Finland. Meteoritics, 7, 547-552.

Walker, D., Grove, T., 1993. Ureilite smelting. Meteoritics 28, 629-636.

Warren, P.H., 2011. Stable isotopes and the noncarbonaceous derivation of ureilites, in common with nearly all differentiated planetary materials. Geochimica et Cosmochimica Acta, 75, 6912-6926.

Warren, P.H., 2012. Parent body depth-pressure-temperature relationships and the style of ureilite anatexis. Meteoritics and Planetary Science, 47, 209-227.

Warren, P.H., Kallemeyn, G.W., 1992. Explosive volcanism and the graphite-oxygen fugacity buffer on the parent asteroid(s) of the ureilite meteorites. Icarus 100, 110-126.

Warren, P.H., Huber, H., 2006. Ureilite petrogenesis: a limited role for smelting during anatexis and catastrophic disruption. Meteoritics \& Planetary Science, 41, 835-849.

Warren, P.H., Rubin, A.E., 2010. Pyroxene-selective impact smelting in ureilites. Geochimica et Cosmochimica Acta, 74, 5109-5133.

Warren, P.H., Rubin, A.E., Isa, J., Brittenham, S., Ahn, I., Choi, B.-G., 2013. Northwest Africa 6693: A new type of FeO-rich, low- $\Delta{ }^{17} \mathrm{O}$, poikilitic cumulate achondrite. Geochimica et Cosmochimica Acta, 107, 135-154.

Wasson, J.T., Chou, C., Bild, R.W., Baedecker, P.A., 1976. Classification of and elemental fractionation among ureilites. Geochimica et Cosmochimica Acta, 40, 1449-1458.

Wilson, L., Goodrich, C.A., Van Orman, J.A., 2008. Thermal evolution and physics of melt extraction on the ureilite parent body. Geochimica et Cosmochimica Acta, 72, 6154-6176.

Wlotzka, F., 1972. Havero ureilite: evidence for recrystallization and partial reduction. Meteoritics, 7, 591-600.Berkley, J.L., Jones, J.H. 1982. Primary igneous carbon in ureilites: Petrological implications. Journal of Geophysical research 87, A353-A364. 

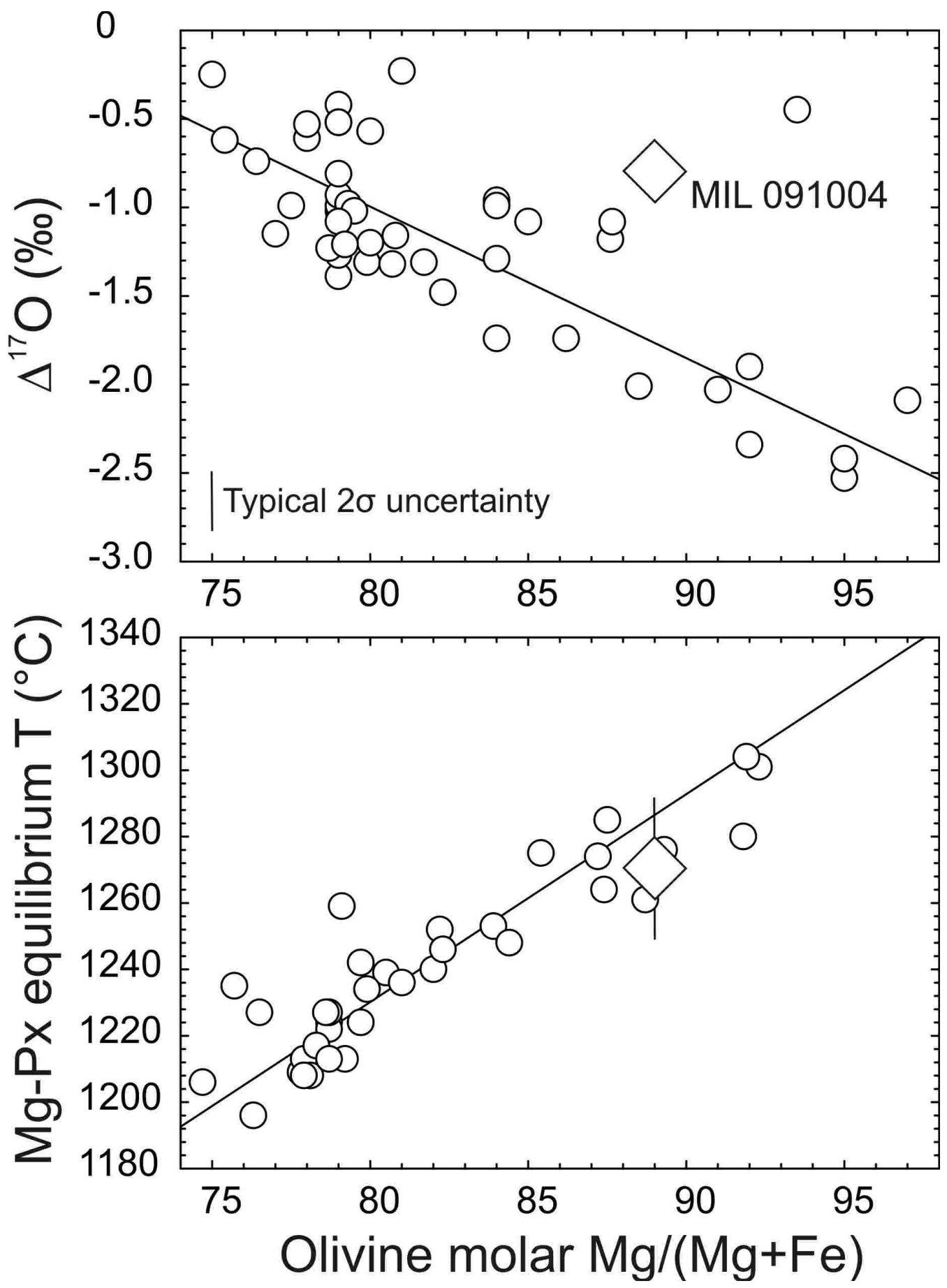

Figure 1 - Olivine core composition (forsterite content as molar $\mathrm{Mg} /(\mathrm{Mg}+\mathrm{Fe})$ ) versus $\Delta{ }^{17} \mathrm{O}$, measured in bulk rock or mineral phases, and calculation of low-Ca pyroxene equilibration using the experimentally calibrated thermometer of Singletary \& Grove (2003). Correlation between Fo and $\Delta^{17} \mathrm{O}$ can be derived as $\Delta^{17} \mathrm{O}=-0.0856 \times[\mathrm{Fo}]+$ $5.8526\left(\mathrm{R}^{2}=0.7\right)$. Correlation between Fo and low-Ca pyroxene $(\mathrm{Mg}-\mathrm{Px})$ equilibration temperature can be derived as $0.1597 \times[\mathrm{Fo}]+116.46,\left(\mathrm{R}^{2}=0.83\right)$. Data are from this 
study, Clayton \& Mayeda (1988), Singletary \& Grove (2003), Downes et al. (2008) and Warren (2012), with associated $2 \sigma$ uncertainties shown.
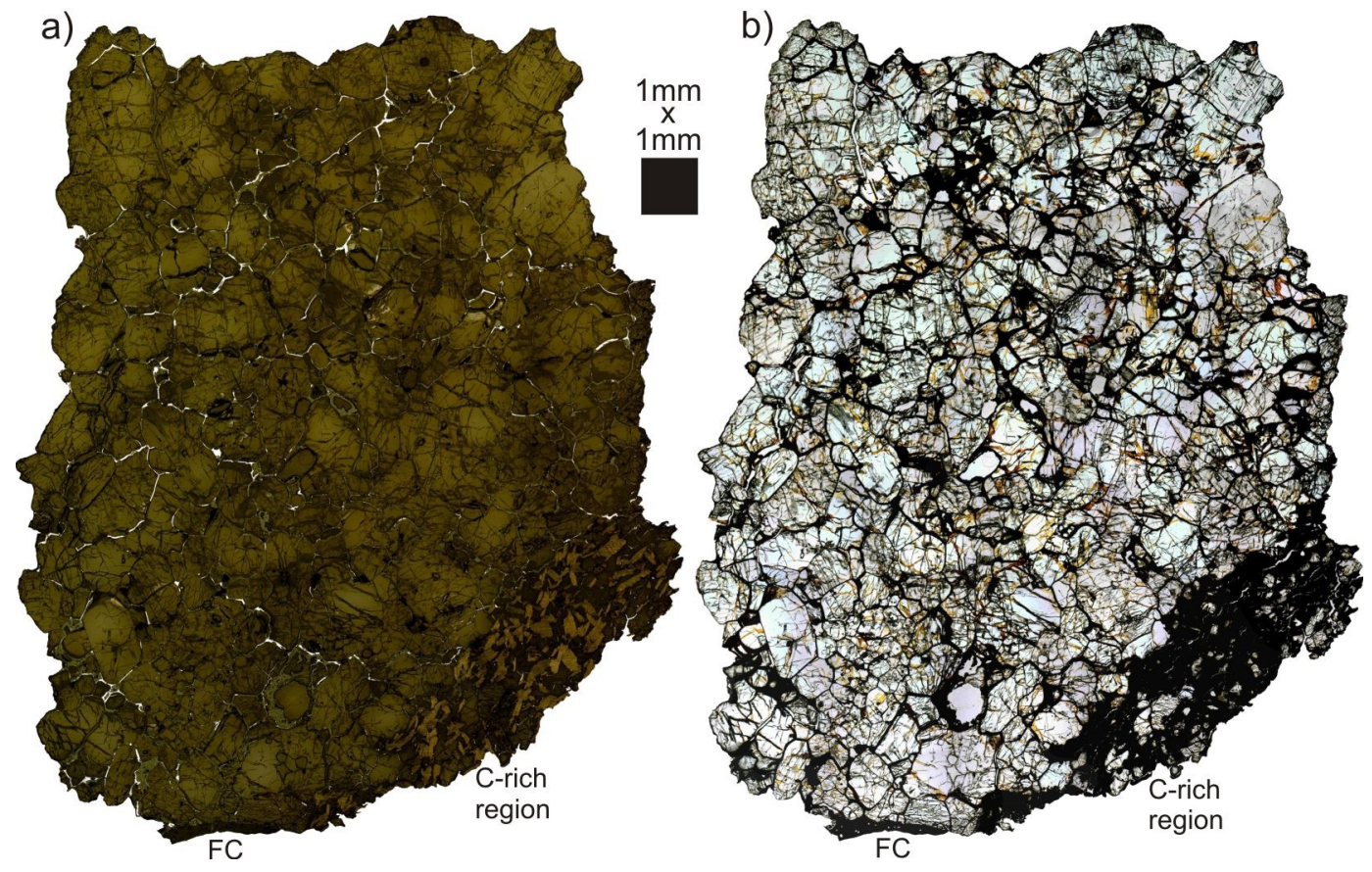

Figure 2 - Composite photomicrograph maps of MIL 091004, 7 in (a) reflected light and (b) plane-polarized light. Carbon grains in the "carbon-rich region" (labeled $C$-rich region) can be seen in the lower-right and lower-center portions of the reflected-light map (light brown, lathlike grains); the same carbon grains are opaque in plane-polarized light. The remainder of the meteorite exhibits a granular texture dominated by olivine and is referred to as the "main silicate region". Along the left-center edge of the section is a region of vesicular fusion crust (labeled $F C$ ). In (a), veins of highly reflective $\mathrm{FeNi}, \mathrm{FeS}$, schreibersite, and products of terrestrial weathering are visible. Scale bars shown. 


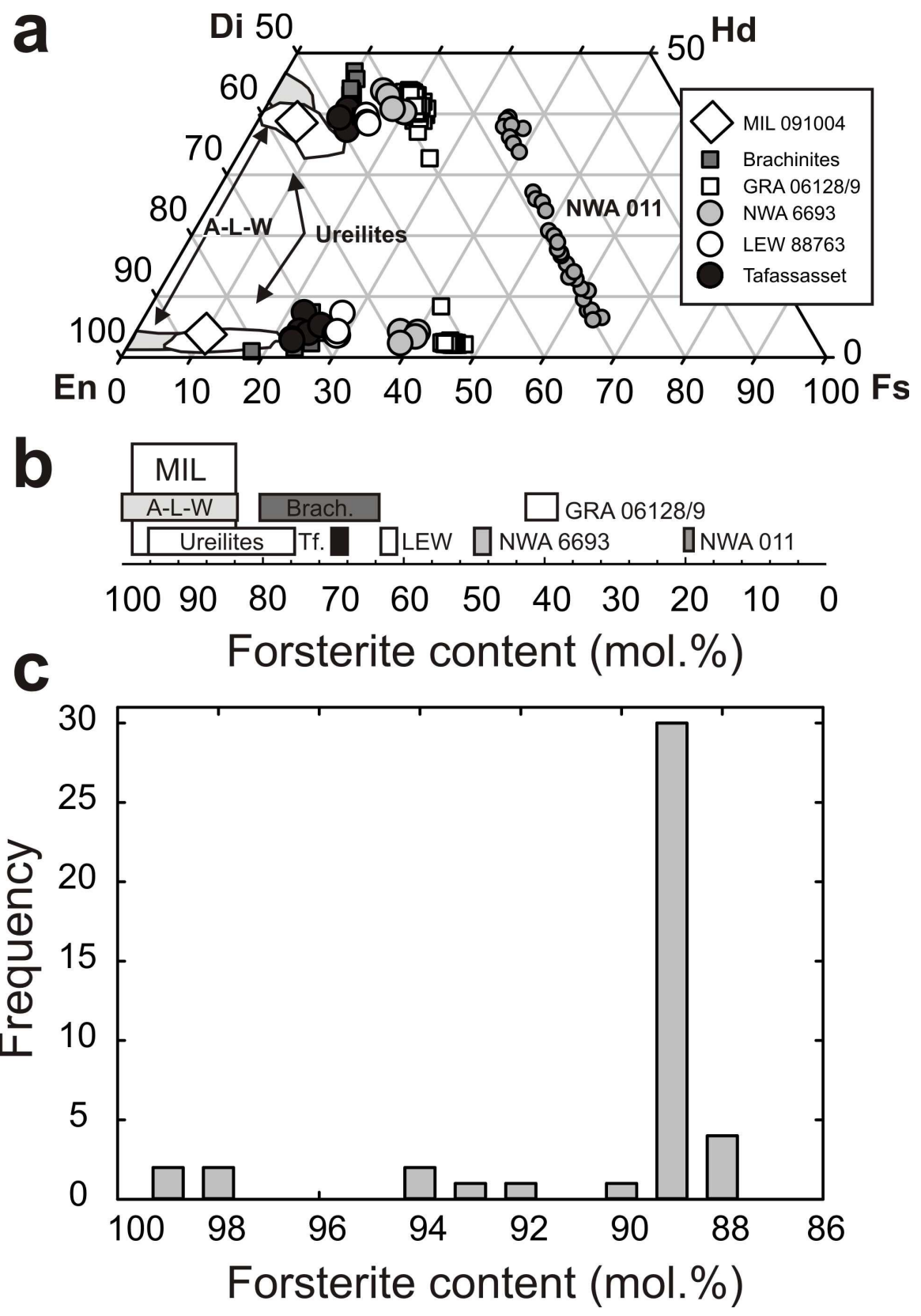

Figure 3 - Pyroxene quadrilateral (a) and olivine forsterite (b) content and (c) histogram diagram for MIL 091004 versus primitive achondrites including: acapulcoite-lodranitewinonaites (A-L-W), ureilites, brachinites (Brach.), Tafassasset (Tf.), NWA 6693, the GRA 06128/9 meteorites, LEW 88763 and NWA 011. (c) Histogram of olivine forsterite contents in MIL 091004. All of the high forsterite content olivine compositions exist proximal to graphite in the C-rich region. Other meteorite data from Benedix et al. (1998); Mittlefehldt et al. (1998); Floss et al. (2005); Day et al. (2012; 2015); GardnerVandy et al. (2012); Warren et al. (2013). 

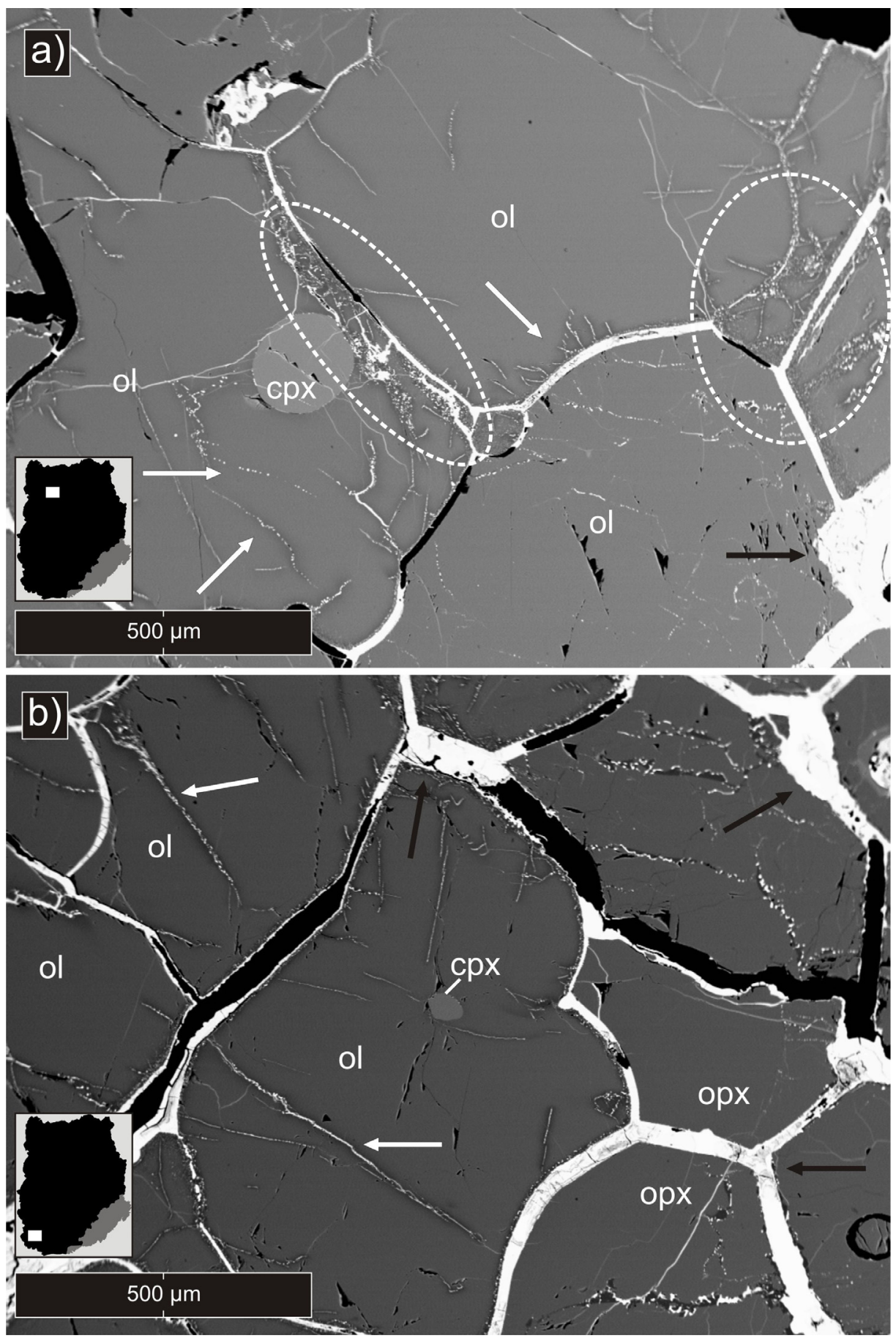

Figure 4 - Back-scatter electron (BSE) images portions of the main silicate region in MIL 091004, 7. Low-Ca pyroxene (opx) and olivine (ol) form discrete grains, whereas highCa pyroxene (cpx) grains are preserved as round inclusions armoured within olivine. Within the main silicate region, fractures in olivine and orthopyroxene contain FeNi metal and are consistent with localized reduction (white arrows and oval stippled regions). Schreibersite and sulfide occur within interstitial veins (black arrows). Insets are 
location maps showing the main silicate region and carbon-rich region (see also Figure 2).

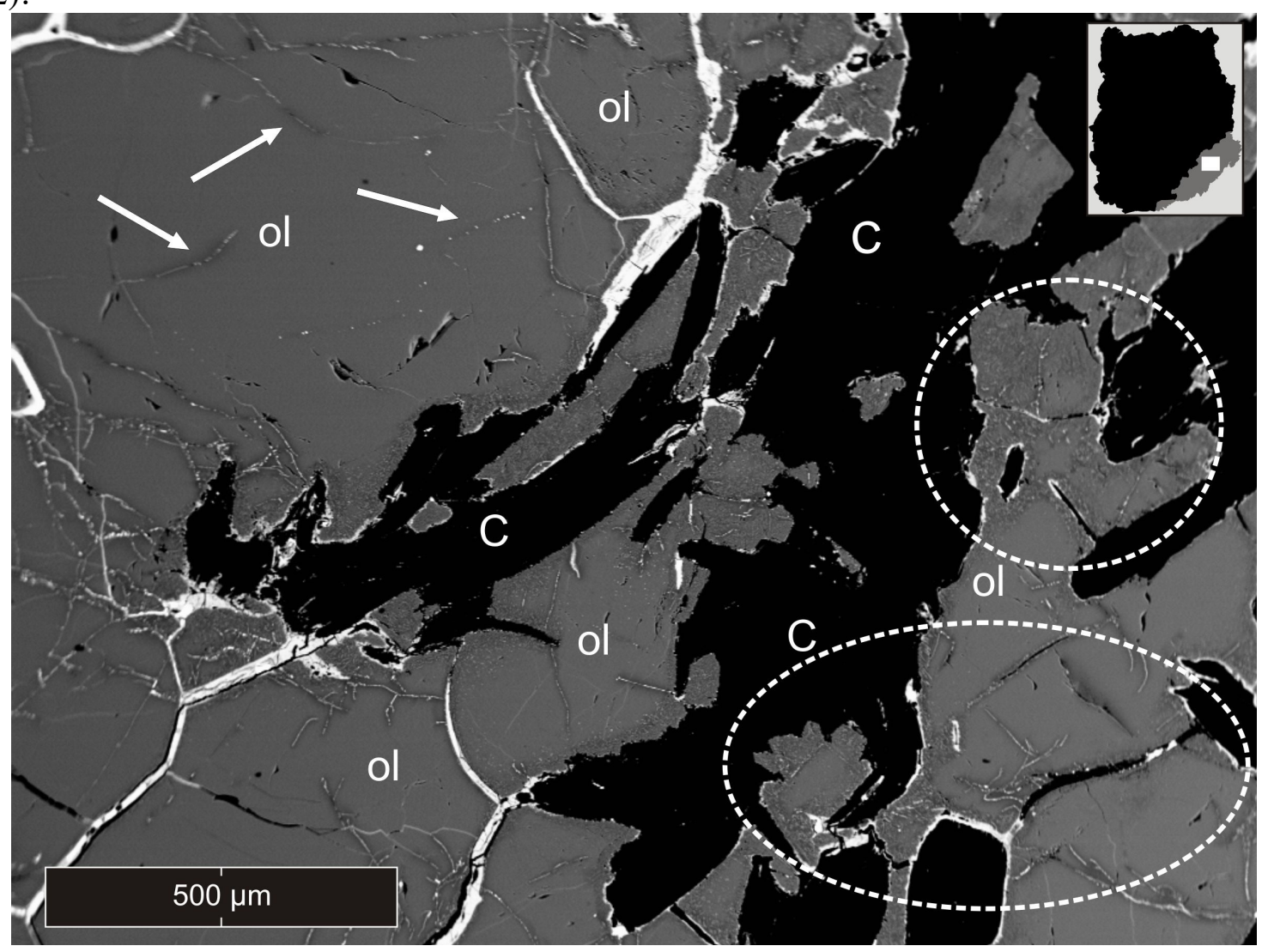

Figure 5 - Back-scatter electron (BSE) image of the carbon-rich region in MIL 091004, 7. In addition to large graphite grains $(>0.5 \mathrm{~mm}$ long), there is abundant evidence for localized reduction of olivine to FeNi grains within fractures (white arrows) and areas of strong reduction within the carbon-rich region (white dashed ovals) where high $\mathrm{Mg} / \mathrm{Fe}$ olivine grains (up to Fo99; dark grey) and FeNi (bright regions) occur, giving a mottled appearance. Volume decrease during the reduction reaction of Fe-bearing olivine to Forich olivine and metal would be consistent with graphite migration, subsolidus, which progressively filled pore space (white dashed oval regions). The graphite grains are aligned and appear to intrude an originally granular texture. Abbreviations: $\mathrm{Ol}=$ olivine; $\mathrm{C}=$ carbon. Inset is a location map showing the main silicate region and carbon-rich region (see also Figure 2). 


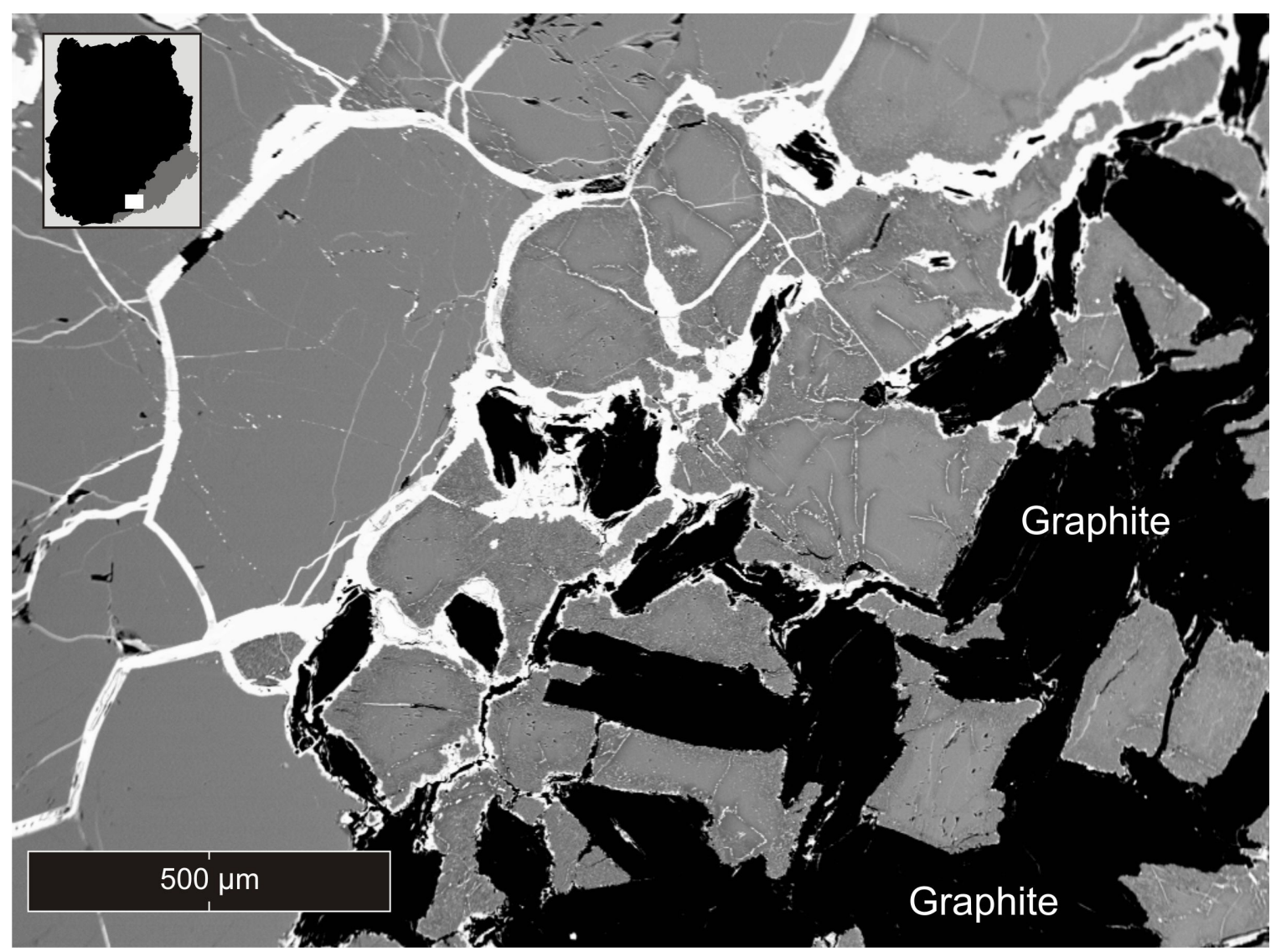

Figure 6 - Back-scatter electron (BSE) image of the boundary between the carbon-rich region and the main silicate region in MIL 091004, 7. Strong reduction of olivine leads to a mottled, streaky appearance in the carbon-rich region. Reduction also occurs in silicates within the main silicate region, but this region is dominated by bright veins of FeNi metal, schreibersite and sulfide. The boundary between the carbon-rich region and the main silicate region is relatively sharp. Inset is a location map showing the main silicate region and carbon-rich region (see also Figure 2). 

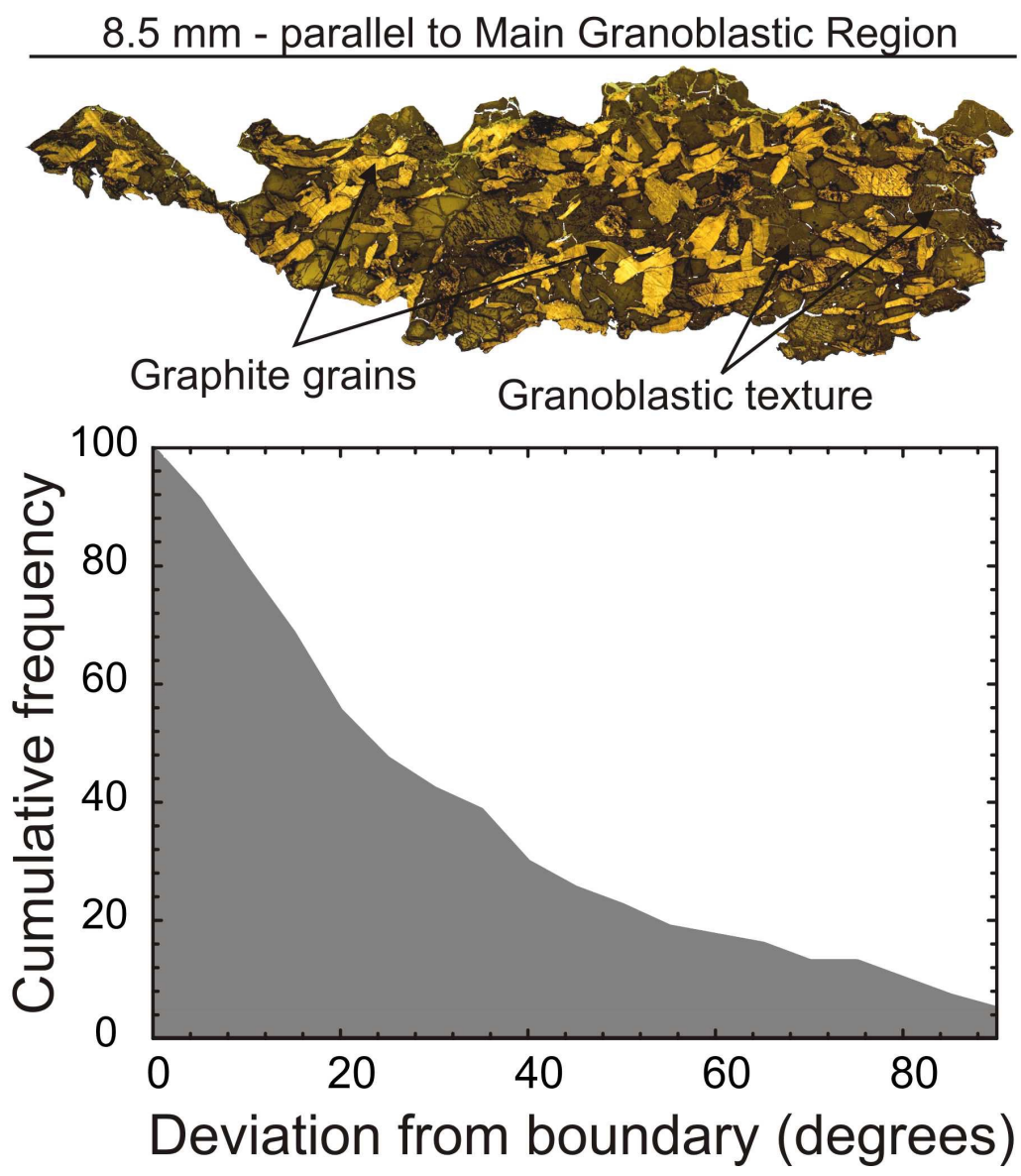

Figure 7 - Layer parellelism of graphite grains in the carbon-rich region of MIL 091004. Top reflected light image shows a false-colour image of the $8.5 \mathrm{~mm}$ long carbon-rich region to illustrate grain relationships parallel to the main silicate region. Noted are granular textures of silicate grains interstitial to rectangular to acicular carbon grains leading to an apparent phaneritic texture. Lower figure shows cumulative frequency plot of 137 carbon grain long-axis angles relative to the boundary between the main silicate region (assumed to be straight). The majority of grains $(\sim 70 \%)$ are oriented to $<40^{\circ}$ with respect to the boundary. 


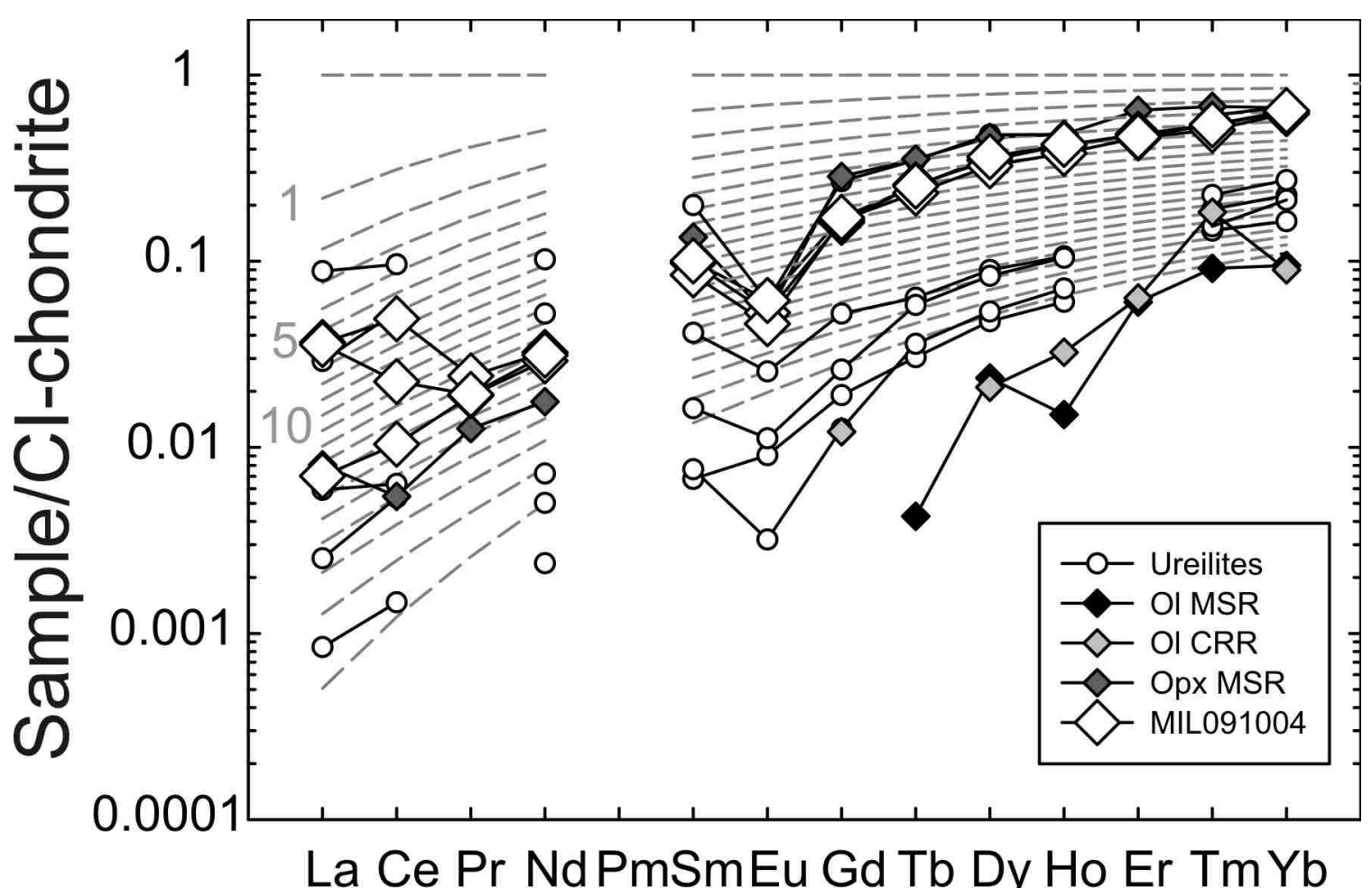

Figure 8 - CI-chondrite rare earth element diagram for MIL 091004 whole-rock, olivine and low-Ca pyroxene in the main silicate region (MSR) and olivine in the carbon-rich region versus REE patterns for other ureilites (Spitz \& Boynton, 1991). A non-modal fractional melting model conforming to a CI chondrite starting compostion is shown, in $1 \%$ increments of melt-extraction. Light REE enrichment ( $\mathrm{La}, \mathrm{Ce}$ ) in some of the wholerock fragments of MIL 091004 likely reflect terrestrial alteration. Partition coefficients and modes are given in the Supplementary Materials. Normalization from McDonough \& Sun (1995). 

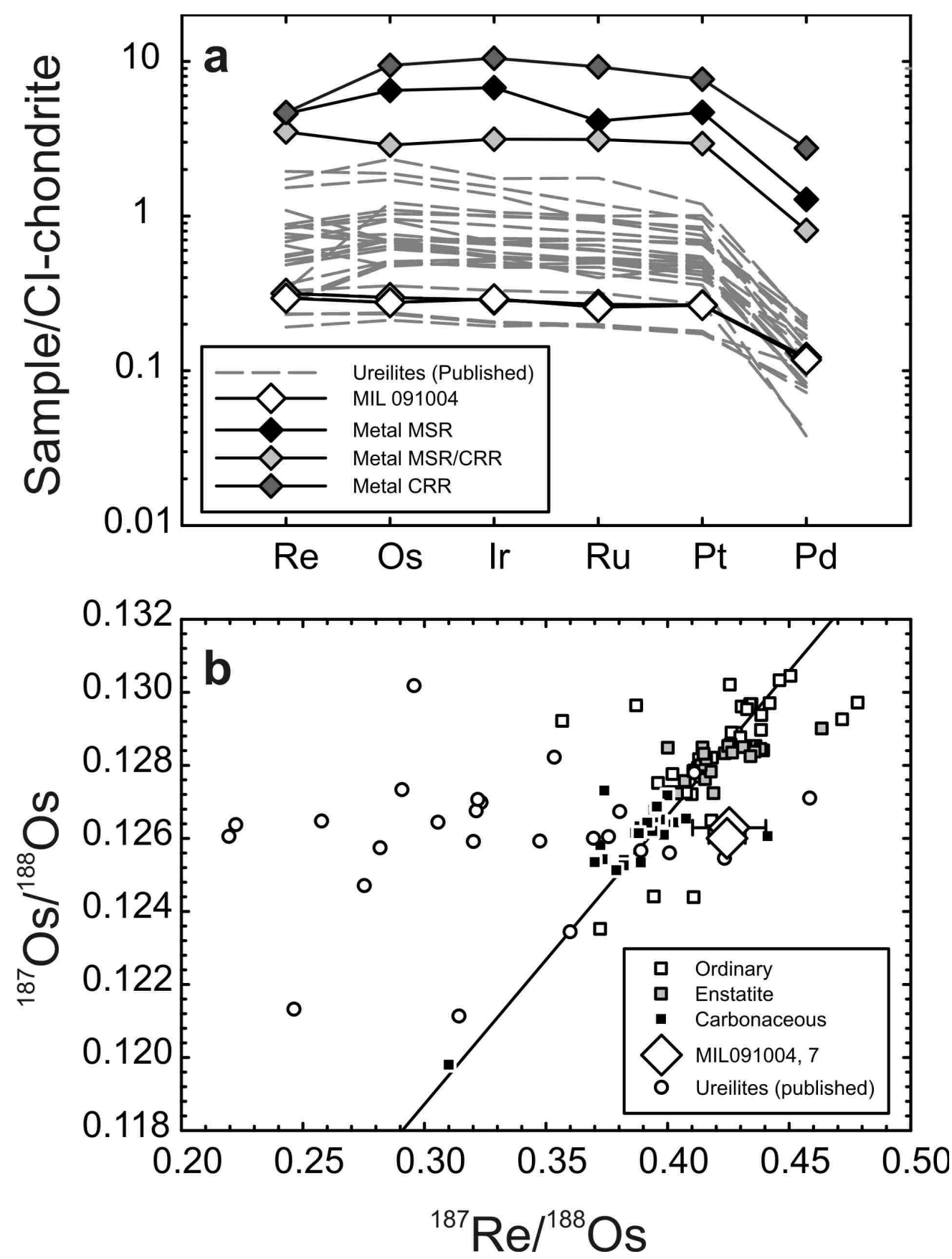

Figure 9 - (a) CI-chondrite normalized highly siderophile element abundances for MIL 091004 whole-rocks and metal versus other ureilites. Metals are from the main silicate region (MSR), carbon-rich region (CRR) and at the boundary between the two regions (MSR/CRR). Ureilite ALH 81101, which has anomalosly low HSE abundances, is omitted from the plot for clarity; (b) Re-Os isotope diagram showing the 4.568 Ga IIIAB iron reference isochron (Smoliar et al., 1996). Published ureilite data are from Rankenburg et al. (2007; 2008). Chondrite normalization and chondrite data are from Horan et al. (2003) and Day et al. (2016). 


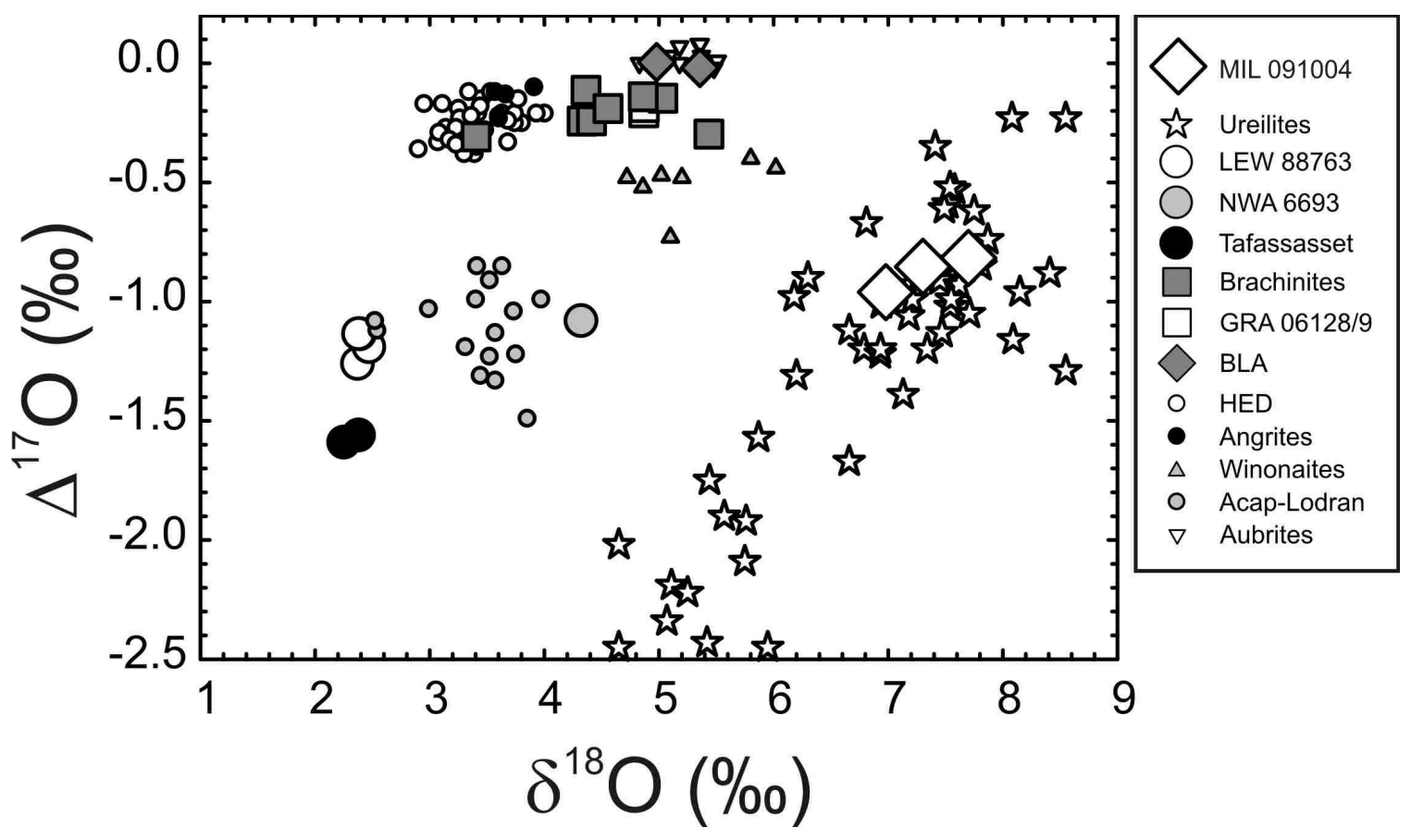

Figure 10 - Oxygen isotope systematics of MIL 091004 as $\delta^{18} \mathrm{O}$ versus $\Delta^{17} \mathrm{O}$, compared with other primitive achondrites. Abbreviations: BLA = brachinite-like achondrites; HED = howardite-eucrite-diogenites; Acap-Lodran = acapulcoite-lodranites. Published data are from Clayton \& Mayeda (1996), Day et al. (2009; 2012; 2015), Greenwood et al. (2012), Gardner-Vandy et al. (2012), Warren et al. (2013) and references therein. 


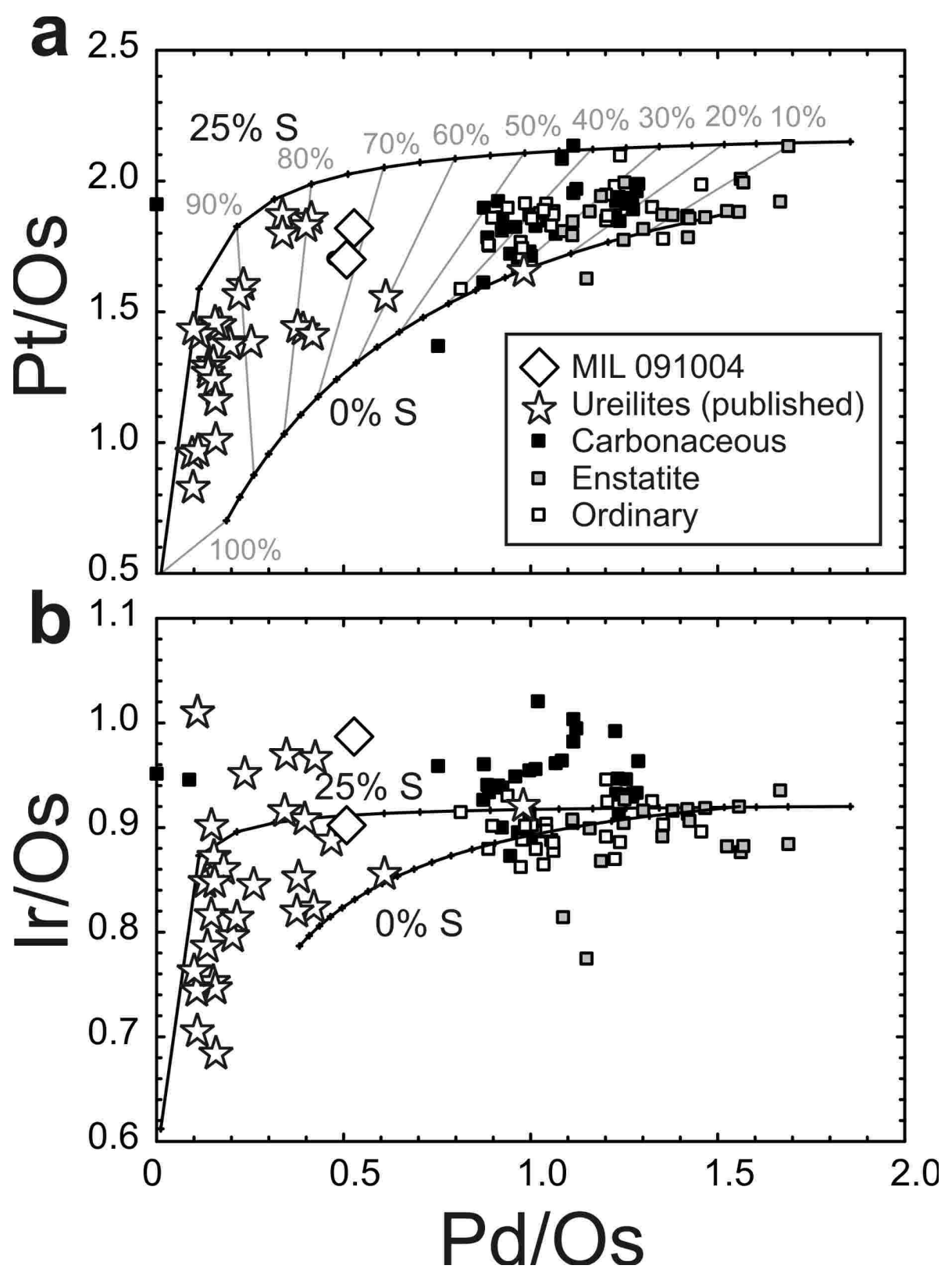

Figure 11 - Plots of $\mathrm{Pd} / \mathrm{Os}$ versus (a) $\mathrm{Pt} / \mathrm{Os}$ and (b) $\mathrm{Ir} / \mathrm{Os}$ ratios for ureilites and chondrites, with calculated compositions of metal residues. Shown are published chondrite (Horan et al., 2003; Fischer-Godde et al., 2010) and ureilite HSE compositions (Rankenburg et al., 2008). The melt calculations model the composition of residues that result from single episodes of batch melting. The starting HSE composition is the bulk composition of Orgueil with concentrations adjusted assuming that all of the HSE were originally in metal and that metal comprises $5 \%$ of the bulk. Curves show compositions of residues resulting from no sulfur, and $25 \%$ sulfur. Fractions of residue are labelled and are in increments of $5 \%$. Solid metal-liquid metal D values were calculated using the parameterization of Chabot \& Jones (2003). Details of the models, D-values used from the parameterization and equations are provided in the text. 


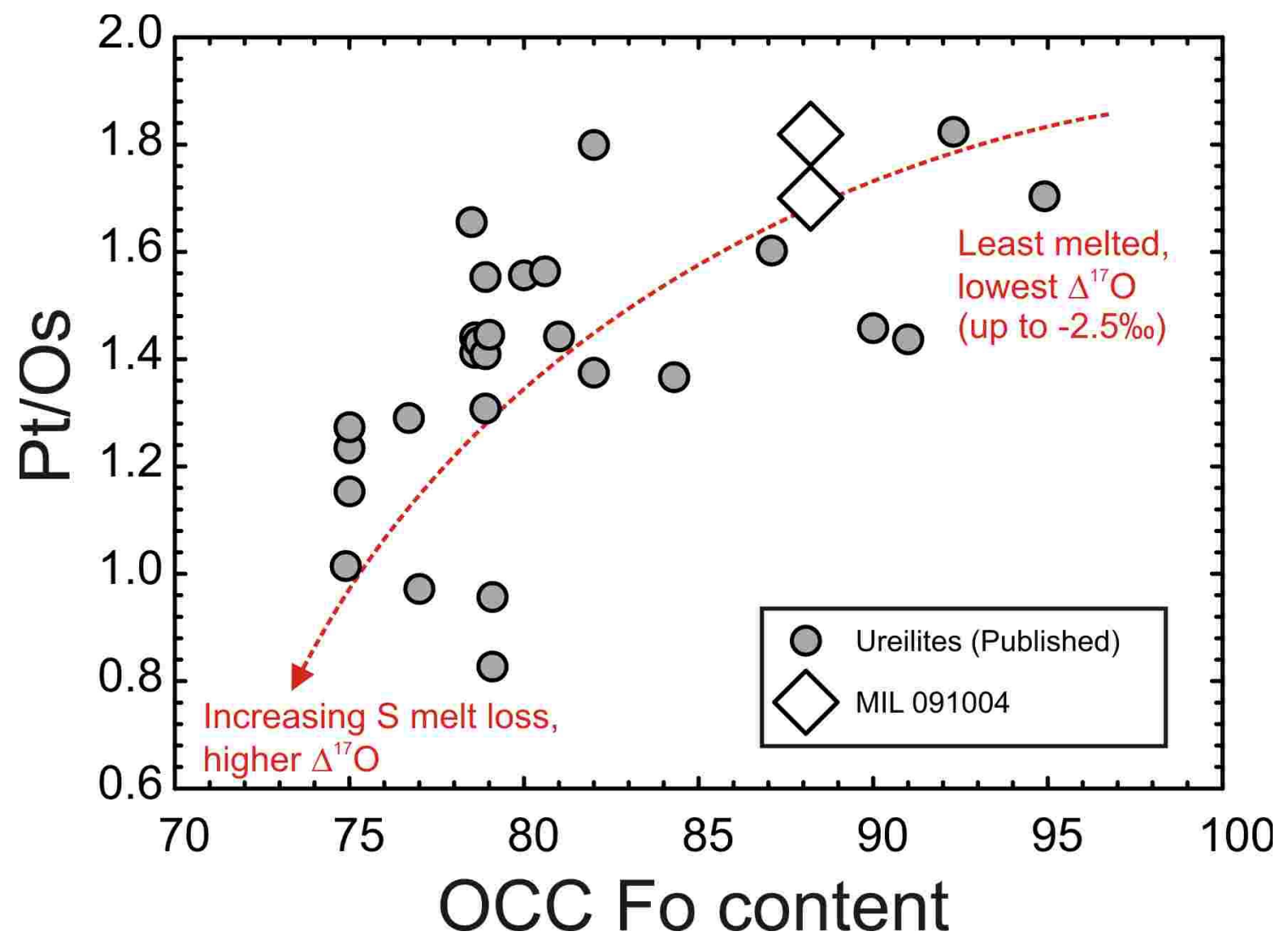

Figure 12 - Average olivine core composition (OCC) for ureilites versus Pt/Os. Data define a correlation with an $\mathrm{R}^{2}$ of 0.4 . Decreasing $\mathrm{Pt} / \mathrm{Os}$ is modelled as resulting from increasing $\mathrm{S}$ melt-loss, consistent with the highest degrees of partial melting and melt extraction in samples with the lowest olivine core composition Fo contents and highest $\Delta^{17} \mathrm{O}$. Data from this study and Rankenburg et al. (2008). 
Table 1 | Average major-element composition (in wt. \%) of silicates, troilite and schreibersite in MIL 091004, 7

\begin{tabular}{|c|c|c|c|c|c|c|c|c|c|c|c|}
\hline \multirow[b]{2}{*}{$\mathrm{n}$} & \multirow{2}{*}{$\begin{array}{c}\text { Olivine } \\
43 \\
\end{array}$} & \multirow[b]{2}{*}{$1 \sigma$} & \multirow{2}{*}{$\begin{array}{c}\text { Ol Cores } \\
35 \\
\end{array}$} & \multirow[b]{2}{*}{$1 \sigma$} & \multirow{2}{*}{$\begin{array}{c}\text { OI Reduced } \\
8\end{array}$} & \multirow[b]{2}{*}{$1 \sigma$} & \multicolumn{2}{|c|}{ Main silicate region } & & \multicolumn{2}{|c|}{ Carbon-rich region } \\
\hline & & & & & & & Cores (28) & Reduced (2) & & Cores (7) & Reduced (6) \\
\hline $\mathrm{SiO}_{2}$ & 40.7 & 0.6 & 40.5 & 0.1 & 41.8 & 0.5 & 40.4 & 41.4 & & 40.6 & 41.9 \\
\hline $\mathrm{TiO}_{2}$ & 0.007 & 0.009 & 0.01 & 0.009 & 0.00 & 0.008 & $<0.03$ & $<0.03$ & & $<0.03$ & $<0.03$ \\
\hline $\mathrm{Al}_{2} \mathrm{O}_{3}$ & 0.039 & 0.009 & 0.04 & 0.007 & 0.04 & 0.012 & 0.04 & $<0.03$ & & 0.04 & 0.04 \\
\hline $\mathrm{Cr}_{2} \mathrm{O}_{3}$ & 0.51 & 0.04 & 0.52 & 0.02 & 0.47 & 0.07 & 0.52 & 0.50 & & 0.51 & 0.46 \\
\hline $\mathrm{MgO}$ & 48.1 & 2.3 & 47.0 & 0.3 & 52.5 & 2.1 & 47.0 & 50.4 & & 47.2 & 53.2 \\
\hline $\mathrm{CaO}$ & 0.303 & 0.012 & 0.30 & 0.010 & 0.31 & 0.018 & 0.30 & 0.28 & & 0.30 & 0.31 \\
\hline $\mathrm{MnO}$ & 0.54 & 0.03 & 0.53 & 0.01 & 0.58 & 0.02 & 0.53 & 0.57 & & 0.53 & 0.59 \\
\hline $\mathrm{P}_{2} \mathrm{O}_{5}$ & 0.02 & 0.01 & 0.02 & 0.01 & 0.01 & 0.01 & $<0.05$ & $<0.05$ & & $<0.05$ & $<0.05$ \\
\hline $\mathrm{FeO}$ & 10.0 & 2.8 & 11.2 & 0.2 & 4.53 & 2.6 & 11.3 & 7.06 & & 11.08 & 3.68 \\
\hline $\mathrm{NiO}$ & 0.008 & 0.008 & 0.01 & 0.008 & 0.01 & 0.007 & $<0.06$ & $<0.06$ & & $<0.06$ & $<0.06$ \\
\hline Total & 100.2 & & 100.1 & & 100.2 & & 100.1 & 100.3 & & 100.2 & 100.1 \\
\hline$\% \mathrm{Fo}$ & 89.5 & 3.0 & 88.2 & 0.2 & 95.3 & 2.7 & 88.2 & 92.7 & & 88.4 & 96.2 \\
\hline$\%$ Fo min & 88.0 & & 88.0 & & 91.9 & & 88.0 & 92.2 & & 88.1 & 91.9 \\
\hline \multirow[t]{2}{*}{$\%$ Fo max } & 98.5 & & 89.0 & & 98.5 & & 89.0 & 93.2 & & 89.0 & 98.5 \\
\hline & \multicolumn{2}{|c|}{ Low-Ca Px MSR } & Augite MSR & \multicolumn{3}{|c|}{ Low-Ca Px CRR } & & Troilite & \multicolumn{3}{|c|}{ Schreibersite } \\
\hline$n$ & 30 & $1 \sigma$ & 11 & $1 \sigma$ & 1 & & & 8 & $1 \sigma$ & 8 & $1 \sigma$ \\
\hline $\mathrm{SiO}_{2}$ & 56.3 & 0.2 & 53.7 & 0.2 & 56.3 & & Si & $<0.03$ & 0.01 & 0.13 & 0.02 \\
\hline $\mathrm{TiO}_{2}$ & 0.10 & 0.01 & 0.18 & 0.01 & 0.09 & & $S$ & 36.5 & 0.1 & 0.21 & 0.03 \\
\hline $\mathrm{Al}_{2} \mathrm{O}_{3}$ & 1.27 & 0.02 & 2.00 & 0.02 & 1.28 & & $\mathrm{Fe}$ & 55.7 & 0.6 & 82.1 & 0.2 \\
\hline $\mathrm{Cr}_{2} \mathrm{O}_{3}$ & 0.98 & 0.02 & 1.16 & 0.03 & 0.97 & & Co & $<0.05$ & 0.01 & 0.11 & 0.01 \\
\hline $\mathrm{MgO}$ & 31.5 & 0.1 & 20.1 & 0.1 & 31.6 & & $\mathrm{Ni}$ & 0.05 & 0.02 & 2.35 & 0.04 \\
\hline $\mathrm{CaO}$ & 2.56 & 0.03 & 18.1 & 0.1 & 2.6 & & $\mathrm{P}$ & $<0.03$ & 0.0 & 15.1 & 0.1 \\
\hline $\mathrm{MnO}$ & 0.52 & 0.01 & 0.40 & 0.01 & 0.52 & & $\mathrm{Mg}$ & $<0.03$ & 0.01 & $<0.03$ & 0.01 \\
\hline $\mathrm{FeO}$ & 6.83 & 0.07 & 4.04 & 0.06 & 6.88 & & $\mathrm{Al}$ & $<0.03$ & 0.01 & $<0.03$ & 0.01 \\
\hline $\mathrm{Na}_{2} \mathrm{O}$ & 0.02 & 0.01 & 0.13 & 0.01 & 0.01 & & $\mathrm{Ti}$ & 0.11 & 0.03 & $<0.03$ & 0.01 \\
\hline \multirow[t]{2}{*}{ Total } & 100.1 & & 99.8 & & 100.3 & & $\mathrm{Cr}$ & 6.0 & 0.5 & n.a. & n.a. \\
\hline & & & & & & & $\mathrm{Mn}$ & 0.26 & 0.05 & n.a. & n.a. \\
\hline Wo & 4.96 & 0.05 & 36.7 & 1.7 & 5.00 & & Total & 98.7 & & 100.1 & \\
\hline En & 84.7 & 0.1 & 56.9 & 1.0 & 84.6 & & & & & & \\
\hline Fs & 10.3 & 0.1 & 6.4 & 1.7 & 10.3 & & & & & & \\
\hline$M g \#$ & 89.1 & 0.1 & 89.9 & 2.3 & 89.1 & & & & & & \\
\hline
\end{tabular}

n.a. $=$ not analyzed. Schreib $=$ Schreibersite. $M g$-number $(\#)=100 \mathrm{MgO} /(\mathrm{MgO}+\mathrm{FeO}))$ in mole per cent. 
Table 2 | Whole-rock abundance data and Mg-number for MIL 091004, 4 (in $\mu \mathrm{g} / \mathrm{g}$ )

\begin{tabular}{|c|c|c|c|c|c|c|c|c|}
\hline Sample & MIL 091004 & MIL 091004 & MIL 091004 & Olivine CRR & & Olivine MSR & Opx MSR & \\
\hline Method & Paar Bomb & Paar Bomb & Teflon & LA-ICP-MS & & LA-ICP-MS & LA-ICP-MS & \\
\hline Weight (g) & 0.021 & 0.041 & 0.009 & $n=3$ & & $n=1$ & $n=2$ & \\
\hline Al & 4917 & 4281 & - & & & & & \\
\hline $\mathrm{Fe}$ & 115686 & 97501 & - & 60972 & 3832 & 65597 & 36033 & 1644 \\
\hline $\mathrm{Mn}$ & 3555 & 3060 & - & & & & & \\
\hline $\mathrm{Mg}$ & 184018 & 161616 & - & & & & & \\
\hline $\mathrm{Ca}$ & 13971 & 11635 & - & & & & & \\
\hline $\mathrm{Na}$ & 814 & 454 & - & & & & & \\
\hline $\mathrm{Li}$ & 0.59 & 0.57 & 0.77 & 1.41 & 0.22 & 1.19 & 0.80 & 0.30 \\
\hline P & 1859 & 1573 & 1926 & & & & & \\
\hline Sc & 15.4 & 12.3 & 15.8 & 15.1 & 0.7 & 14.6 & 35.8 & 0.2 \\
\hline $\mathrm{Ti}$ & 375 & 288 & 351 & 25 & 0 & 30 & 334 & 8 \\
\hline V & 90 & 69 & 87 & 60 & 2 & 63 & 135 & 4 \\
\hline $\mathrm{Cr}$ & 4692 & 4055 & 4509 & 3217 & 170 & 3280 & 6343 & 229 \\
\hline $\mathrm{Ni}$ & 832 & 672 & 1225 & 16 & 3 & 78 & 19 & 21 \\
\hline Co & 90.3 & 82.4 & 83.5 & & & & & \\
\hline $\mathrm{Cu}$ & 5.7 & 4.6 & 6.5 & 0.1 & 0.0 & 5.6 & 1.0 & 0.1 \\
\hline $\mathrm{Zn}$ & 107.6 & 86.7 & 120.9 & 249.4 & 10.2 & 268.0 & 190.9 & 3.8 \\
\hline Ga & 4.2 & 3.5 & 3.9 & & & & & \\
\hline Ge & 2.2 & 1.8 & 2.1 & & & & & \\
\hline $\mathrm{Rb}$ & 0.013 & 0.012 & 0.022 & 0.004 & 0.004 & $\mathrm{BDL}$ & 0.001 & 0.009 \\
\hline $\mathrm{Sr}$ & 0.30 & 0.29 & 1.97 & 0.01 & 0.02 & 0.005 & 0.58 & 0.26 \\
\hline Y & 0.572 & 0.500 & 0.574 & 0.066 & 0.012 & 0.076 & 0.792 & 0.010 \\
\hline $\mathrm{Zr}$ & 0.145 & 0.180 & 0.651 & 0.002 & 0.003 & 0.003 & 0.080 & 0.030 \\
\hline $\mathrm{Nb}$ & 0.008 & 0.008 & 0.018 & 0.011 & 0.004 & 0.010 & 0.016 & 0.002 \\
\hline Cs & 0.001 & 0.002 & 0.016 & & & & & \\
\hline $\mathrm{Ba}$ & 0.044 & 0.054 & 109.1 & 0.0038 & 0.0041 & 0.0107 & BDL & \\
\hline La & 0.002 & 0.009 & 0.008 & 0.0017 & 0.0029 & 0.0026 & 0.0019 & 0.0015 \\
\hline $\mathrm{Ce}$ & 0.006 & 0.030 & 0.014 & 0.0009 & 0.0016 & BDL & 0.0033 & 0.0029 \\
\hline $\mathrm{Pr}$ & 0.002 & 0.002 & 0.002 & BDL & & BDL & 0.0012 & 0.0005 \\
\hline $\mathrm{Nd}$ & 0.013 & 0.015 & 0.014 & BDL & & BDL & 0.0080 & 0.0045 \\
\hline Sm & 0.014 & 0.012 & 0.015 & BDL & & BDL & 0.0199 & 0.0047 \\
\hline Eu & 0.003 & 0.003 & 0.003 & BDL & & BDL & 0.0029 & 0.0002 \\
\hline Gd & 0.032 & 0.033 & 0.034 & BDL & & 0.0024 & 0.0569 & 0.0295 \\
\hline Tb & 0.009 & 0.008 & 0.009 & 0.0002 & 0.0003 & BDL & 0.0128 & 0.0017 \\
\hline Dy & 0.086 & 0.080 & 0.090 & 0.0058 & 0.0019 & 0.0052 & 0.1140 & 0.0256 \\
\hline Ho & 0.023 & 0.021 & 0.023 & 0.0008 & 0.0007 & 0.0018 & 0.0262 & 0.0011 \\
\hline $\mathrm{Er}$ & 0.077 & 0.074 & 0.075 & 0.0097 & 0.0010 & 0.0101 & 0.1037 & 0.0022 \\
\hline Tm & 0.013 & 0.013 & 0.013 & 0.0023 & 0.0001 & 0.0045 & 0.0168 & 0.0016 \\
\hline $\mathrm{Yb}$ & 0.101 & 0.100 & 0.104 & 0.0153 & 0.0015 & 0.0145 & 0.1076 & 0.0023 \\
\hline Lu & 0.017 & 0.017 & 0.016 & 0.0045 & 0.0014 & 0.0048 & 0.0241 & 0.0035 \\
\hline $\mathrm{Hf}$ & 0.006 & 0.007 & 0.013 & 0.0003 & 0.0005 & BDL & 0.0081 & 0.0019 \\
\hline Ta & 0.008 & 0.012 & 0.009 & 0.0003 & 0.0003 & BDL & 0.0012 & 0.0005 \\
\hline W & 0.165 & 0.301 & 0.130 & & & & & \\
\hline $\mathrm{Pb}$ & 0.004 & 0.019 & 0.104 & 0.003 & 0.004 & 0.020 & 0.015 & 0.009 \\
\hline Th & 0.001 & 0.003 & 0.002 & 0.022 & 0.039 & BDL & 0.133 & 0.129 \\
\hline U & 0.002 & 0.007 & 0.001 & BDL & & BDL & BDL & \\
\hline
\end{tabular}

Full data including standard values are reported in the Supplementary Information. 


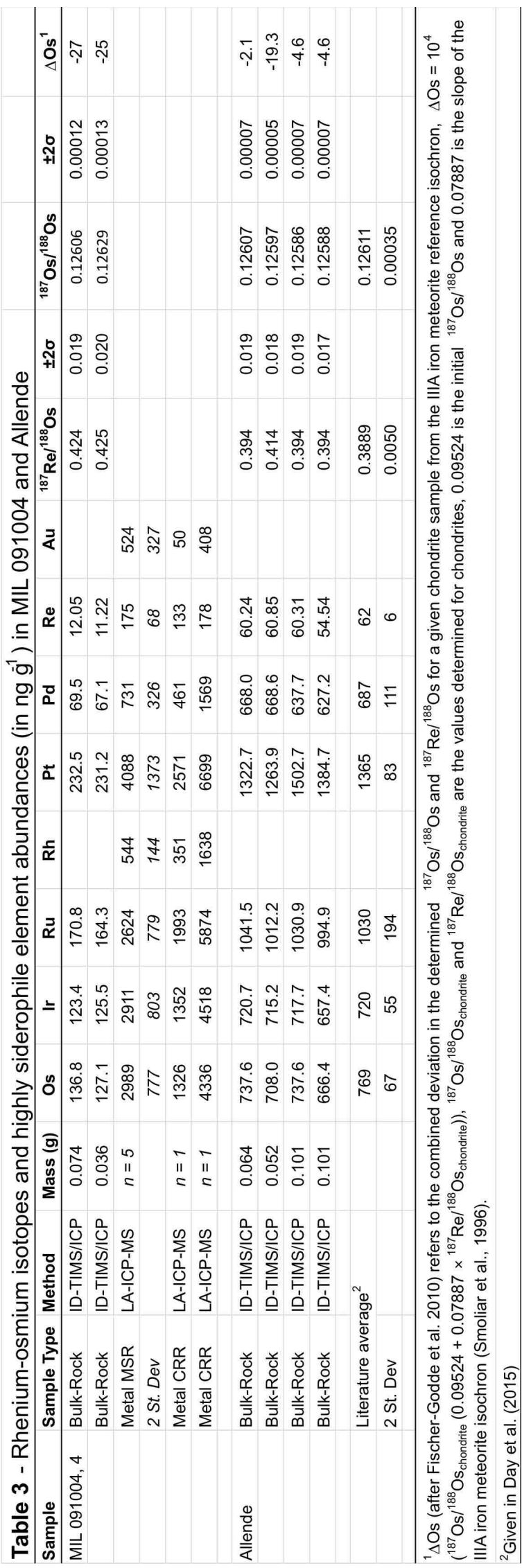

